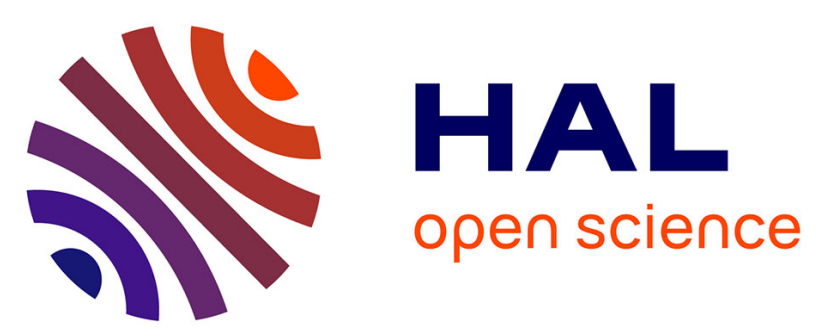

\title{
Environmental and economic assessment of pavement construction and management practices for enhancing pavement sustainability
}

\author{
João Miguel Santos, Gerardo Flintsch, Adelino Ferreira
}

\section{- To cite this version:}

João Miguel Santos, Gerardo Flintsch, Adelino Ferreira. Environmental and economic assessment of pavement construction and management practices for enhancing pavement sustainability. Resources, Conservation and Recycling, 2017, 116, pp.15-31. 10.1016/j.resconrec.2016.08.025 . hal-01644558

\author{
HAL Id: hal-01644558 \\ https://hal.science/hal-01644558
}

Submitted on 22 Nov 2017

HAL is a multi-disciplinary open access archive for the deposit and dissemination of scientific research documents, whether they are published or not. The documents may come from teaching and research institutions in France or abroad, or from public or private research centers.
L'archive ouverte pluridisciplinaire HAL, est destinée au dépôt et à la diffusion de documents scientifiques de niveau recherche, publiés ou non, émanant des établissements d'enseignement et de recherche français ou étrangers, des laboratoires publics ou privés. 
1 Environmental and economic assessment of pavement construction and 2 management practices for enhancing pavement sustainability

\section{Joao Santos (Corresponding Author)}

4 IFSTTAR, AME-EASE, Route de Bouaye, CS4, F-44341 Bouguenais, France

$5 \quad$ Email: joao.oliveira-dos-santos@ifsttar.fr

6 Gerardo Flintsch, Ph.D., P.E.

7 Center for Sustainable Transportation Infrastructure, Virginia Tech Transportation Institute, The 8 Charles Via, Jr. Department of Civil and Environmental Engineering, Virginia Polytechnic Institute and 9 State University, 3500 Transportation Research Plaza, Blacksburg, VA 24061, USA, Email: 10 flintsch@vt.edu

11 Adelino Ferreira, Ph.D.

12 Road Pavements Laboratory, Research Center for Territory, Transports and Environment, Department 13 of Civil Engineering, University of Coimbra, Rua Luís Reis Santos, 3030-788, Coimbra, Portugal, 14 Email: adelino@dec.uc.pt 


\section{Environmental and economic assessment of pavement construction and 2 management practices for enhancing pavement sustainability}

\section{Abstract}

4 Stakeholders in the pavement sector have been seeking new engineering solutions to move towards 5 more sustainable pavement management practices. The general approaches for improving pavement 6 sustainability include, among others, reducing virgin binder and virgin aggregate content in HMA and 7 WMA mixtures, reducing energy consumed and emissions generated in mixtures production, applying 8 in-place recycling techniques, and implementing preventive treatments. In this study, a comprehensive 9 and integrated pavement life cycle costing- life cycle assessment model was developed to investigate, from a full life cycle perspective, the extent to which several pavement engineering solutions, namely hot in-plant recycling mixtures, WMA, cold central plant recycling and preventive treatments, are efficient in improving the environmental and economic dimensions of pavement infrastructure sustainability, when applied either separately or in combination, in the construction and management of a road pavement section located in Virginia, USA. Furthermore, in order to determine the preference order of alternative scenarios, a multicriteria decision analysis method was applied. The results showed that the implementation of a recycling-based maintenance and rehabilitation strategy where the asphalt mixtures are of type hot-mix asphalt containing 30\% RAP, best suits the multidimensional and conflicting interests of decision-makers. This outcome was found to be robust even when different design and performance scenarios of the mixtures and type of treatments are considered.

Keywords: life cycle costing, life cycle assessment; in-place recycling techniques; sustainable pavement construction and management; multi-criteria decision analysis. 


\section{Introduction}

With the recent launch of the Build America Investment Initiative (White House, 2014), a US government-wide initiative that aims to tackle the pressing infrastructure investment needs of the United States as well as to promote economic growth, many Departments of Transportation (DOTs) will likely renew their efforts both in the construction of new highway infrastructures and in the maintenance of those already built.

The activities underlying to the construction, operation and maintenance of highway infrastructures are notorious for the large amounts of natural materials and energy resources they consume, as well as for the considerable environmental impacts they generate (BCRB and HCA, 2011). In addition, the strong and growing evidence of the environmental effects of these activities, along with stringent environmental regulations, has strengthened the commitment of DOTs in delivering infrastructures in a more environmentally preferable way, while also using funds in the most economically responsible manner possible. This fact has motivated DOTs, and the pavement community in general, to investigate strategies that improve the environmental performance and reduce the costs of road pavement construction and maintenance practices by using sustainable engineering solutions. Some examples of solutions commonly mentioned in the literature that possess the potential to improve pavement sustainability include (but are not limited to): (1) asphalt mixes requiring lower manufacturing temperatures, such as warm mix asphalt [WMA] (Kristjánsdóttir et al., 2007; Hamzah et al., 2010; Tatari et al., 2012; Vidal et al., 2013; Mohammad et al., 2015; Rodríguez-Alloza et al., 2015) and halfwarm mix asphalt [HWMA] technologies (Rubio et al., 2013), (2) in-place pavement recycling (Thenoux et al., 2007; Robinette and Epps, 2010; Santos et al., 2015c), (3) pavement preservation strategies and preventive treatments (Giustozzi et al., 2012), (4) long-lasting pavements (Lee et al., 2011; Sakhaeifar et al., 2013), (5) reclaimed asphalt pavement (RAP) materials (Lee et al., 2010; Aurangzeb et al., 2014), (6) reclaimed asphalt shingles (RAS) materials (Illinois Interchange, 2012), (7) industrial wastes and byproducts (Birgisdóttir et al., 2006; Carpenter et al., 2006; Carpenter and Gardner, 2009; Huang et al., 2009; Lee et al., 2010; Sayagh et al., 2010; Mladenovič et al., 2015), etc.

Despite the fact that the majority of the results of those studies have to some extent corroborated the environmental benefits with which they are a-priori associated, it is not uncommon that they have been obtained by applying methodologies that disregarded the environmental burdens of some processes and pavement life cycle phases. Added to this, as the primary goal of a transportation agency still remains to provide maximum pavement performance within budgetary constraints, a solution which is found environmentally advantageous might not be preferred to another one technically equivalent if it is not economically competitive. Furthermore, there are still some questions about (1) the extent to which such solutions are cost effective throughout their life cycle, (2) which factors are the key drivers of their economic performance, and (3) who are the stakeholders that benefit most from the application of those solutions.

Facing this bicephalous challenge and providing answers to the aforementioned questions requires multidimensional life-cycle modelling approaches, such as life-cycle assessment (LCA) and life cycle costing (LCC), which enable long-term economic and environmental factors to be included in the decision- making process by providing a comprehensive and cumulative view of both the environmental and economic dimensions of a given technical solution. However, it is important to underline that lifecycle modelling approaches by themselves will not necessarily determine which solution is most suitable for a given purpose. Rather, the information that they make available should be used as one component of a more comprehensive decision making process, which among other merits, will allow the tradeoffs between the interests of the multiple stakeholders to be assessed.

\section{Objectives}


1 The main objectives of this paper are (1) to investigate from a life cycle perspective the extent to which several pavement engineering solutions, namely hot in-plant recycling mixtures, WMA, cold central plant recycling (CCPR) and preventive treatments, are efficient in improving the environmental and economic dimensions of pavement infrastructure sustainability, when applied either separately or in combination, in the construction and management of a road pavement structure and (2) to raise awareness of the importance of extending the system boundaries of environmental and economic life cycle assessments, in order to include materials and processes which, when taken into consideration, may eventually reverse the sustainability of a solution, in comparison to the situations where they are not accounted for.

For this purpose, a comprehensive and integrated pavement life cycle costing-life cycle assessment (LCC-LCA) model has been developed, which encompasses all six pavement life cycle phases into the system boundaries, including the usage phase, and accounts for the upstream impacts in the production of elements commonly disregarded by the majority of the existing pavement LCA models.

Finally, to account for the often conflicting interests of the multiple stakeholders involved in the decision making process within pavement management, the pavement construction and maintenance scenarios considered in this paper were further analyzed by employing a multi-criteria decision making (MCDM) method.

\section{Background to the life cycle modeling approaches adopted in the proposed framework 3.1. Life cycle assessment}

LCA is a widespread, though still evolving, systematic environmental management tool used for assessing the potential environmental impacts and resources consumed throughout a product's lifecycle from a cradle-to-grave perspective, i.e., from raw material acquisition, via production and use phases, to the end-of-life phase.

The LCA approach formalized by the ISO 14040 series divides the LCA framework into four iteractive stages (ISO, 2006a,b): (i) goal and scope definition; (ii) life cycle inventory analysis (LCI); (iii) life cycle impact assessment (LCIA); and (iv) interpretation. The goal and scope definition introduces the purpose for carrying out the study, the intended application, and the intended audience. It is also in this stage that the system boundaries of the study are described and the functional unit is defined. The LCI compiles the inputs (resources) and the outputs (emissions) from the product over its life-cycle in relation to the functional unit. The LCIA seeks to establish a linkage between the system and the potential to cause human and environmental damage. In the interpretation, the results from the previous phases are evaluated in relation to the goal and scope in order to identify analysis refinements and improvements, reach conclusions and recommendations, and, in general, aid in the decision-making process (Finnveden et al., 2009).

On the basis of the approaches for compiling the LCI, an LCA methodology can be classified into three main categories: (i) process-based LCA (P-LCA); (ii) input-output LCA (I-O LCA); and (iii) hybrid LCA.

In the P-LCA, process-specific data for each process of the product life cycle is compiled to form a tailored process diagram that covers the whole life cycle. Each of the diverse processes within the system boundaries is then thoroughly analyzed, which leads to very accurate LCI results. However, due to the commonly high number of single processes existing in a product life cycle, accounting for all of them can be a time consuming and detail-intensive procedure. A P-LCA practitioner has to define which processes are included within the chosen system boundaries. Ideally, those that are left out should have an insignificant contribution to the results. However, due to the fact that decisions on the inclusion or exclusion of processes are commonly taken on the basis of subjective choices rather than on a scientific basis, it might happen that significant processes are also left out of the analysis along with the insignificant ones. This problematic feature of P-LCA method is known as truncation error. 
The I-O LCA is a top-down approach that relies on the theory introduced and developed by Nobel Prize winner Wassily Leontief (Leontief, 1970). It uses available sectorial monetary transaction matrixes describing complex interdependencies of industries in an economy to estimate the sector level environmental burdens and the resources consumed throughout the upstream supply-chain to deliver a certain amount of different goods and services (Suh et al., 2004).

Although the I-O LCA method eliminates the truncation error by tracking all upstream processes, there are several drawbacks: (i) it uses aggregate data representing the averages of several sectors of an economy, and aggregate industry sectors may make the method unable to provide information on the particular product or activity under investigation, such as specific raw materials and energy sources, and to compare similar products within an industry sector, especially if the product falls into a sector which is broadly characterized; (ii) from the I-O LCA practitioner's perspective it may look like a "black box", because comprehensively analyzing a specific process is always impossible; (iii) monetary value, the most commonly used representation of inter-industry transactions, can distort physical flow relations between industries due to price inhomogeneity; (iv) the proportionality assumption, according to which the inputs to a sector are assumed to be linearly proportional to its output, represent another source of errors given that in practice it is not always true; (v) available I-O tables are generally several years old. Thus, assessing rapidly developing sectors and new technologies may introduce errors because of base-year differences between the product system under study and I-O data; and (vi) data used in the I-O model are incomplete, with inherent uncertainties, thus, potentially, underestimating results such as environmental impacts (Suh et al., 2004). Quantitative evaluations of the limitations of both P-LCA and I-O LCA models are presented by Junnila (2006), Ferrão and Nhambiu (2009), Mattila et al. (2010), Majeau-Bettez et al. (2011).

To combine the advantage of both P-LCA and I-O LCA models while mitigating their respective limitations, four main hybrid LCA models have been developed, namely tiered, input-output-based, integrated hybrid (Suh et al., 2004) and augmented process-based approach (Bilec et al., 2006,2010). Although significant differences distinguish the inventory stage of those models (Suh and Huppes, 2005), all are based on the principle of a disaggregated and detailed process-based description of the most important activities linked to an aggregated but complete model of the rest of the economy (Majeau-Bettez et al., 2011). In doing so, it allows for flows which were not included in the P-LCA to be estimated with an environmentally extended I-O model. A review of LCI approaches including hybrid approaches and their advantages and disadvantages is provided by Suh and Huppes (2005) and Bilec et al. (2006).

\subsection{Life cycle costing}

Life cycle costing (LCC) is defined by the building and construction asset standard ISO15686-5 as a technique used for predicting and assessing the cost performance of constructed assets over a specific period of time while meeting all the functional and operational maintenance and other performance requirements, taking into account all relevant economic factors, both in terms of initial and future operational costs (ISO, 2008).

Despite the (often) hypothetical ambiguities generated by the term "life cycle", shared by LCC and LCA, this methodology was initially developed by the US Department of Defense in the mid-sixties (Sheriff and Kolarik, 1981), and to a large extent, its maturation process occurred outside the environmental context (Gluch and Baumann, 2004). The abovementioned standards already allude the possibility of including inputs from other evaluation techniques (e.g. environmental assessment). Similar intents were also expressed in the revised framework ISO 14040 by claiming that “...LCA typically does not address the economic or social aspects of a product, but the life-cycle approach and methodologies described in this International Standard may be applied to these other aspects." (ISO, 2006a). However, the most expressive step towards its integration into the environmental decision 
making process was taken first by Hunkeler et al. (2008), and, later, by Swarr et al. (2011), through the disclosure of a code of practice that builds on the four-phase structure of the ISO 14040 standards (ISO, 2006a). This code of practice aims to provide guidance on how to define consistent system boundaries for complementary and parallel LCC and LCA studies of a given product system.

On the basis of the approach adopted to account for the externalities, Hunkeler et al. (2008) divide LCC into conventional, environmental or societal. Conventional LCC is a collection of all costs associated with the life cycle of a product that are directly covered by the main producer or user in the product life cycle. Environmental LCC, on the other hand, assesses the costs associated with the life cycle of a product, covered by one or more of the actors involved in the life cycle of the product, and also includes the externalities that might be internalized and reflected in real monetary flows within a foreseeable time frame. Another point that distinguishes this approach from the previous one lies with the fact that it also requires a complementary LCA with equivalent system boundaries and functional units. However, in this LCA-type LCC based on physical LCA, there is no conversion from environmental measures to monetary measures in order to avoid double counting of externalities in LCC and the complementary LCA. Finally, in the Societal LCC the scope is extended to the macroeconomic system level, including costs for society overall. Environmental costs are defined as either environmental damage expressed in monetary terms (costs of external effects), or as the market-based cost of measures to prevent environmental damage. However, to avoid double counting, the monetized environmental effects of the investigated product should not be complemented by an LCA.

\section{Methodology}

\subsection{Principle of the integrated pavement life cycle costing and life cycle assessment model}

The research work presented in this paper builds on the P-LCA and LCC models introduced by Santos et al. (2015a,c) and Santos et al. (2015b), respectively, to develop a comprehensive and integrated pavement LCC-LCA model. The proposed pavement LCC-LCA model relies on a hybrid inventory approach that allows the sub-models to connect with one another by data flows; specifically, the monetary flows associated with exchanges of the pavement life cycle system that are directly covered by the LCC model but for which specific process data are either completely or partially unavailable. In other cases it is available, but collection of the data and subsequent analysis is highly demanding, either in time or resource consumption (e.g. construction equipment manufacturing and maintenance, on- and off-road vehicles tires manufacturing, lubricant oil production, etc.) and, thus, was disregarded in the previous P-LCA models (Santos et al., 2015a,c). These are combined with the I-O methodology for deriving the underpinning environmental burdens. Thus, by interactively integrating the strengths of process-based LCI (P-LCI) and I-O LCI, the resources which are readily available can be used in a more efficient, consistent and rational way and with less effort, helping to reduce the "cutoff" errors and improving the consistency between the system boundaries of the pavement life cycle when analyzed concomitantly from the economic and environmental viewpoint. For this purpose, the pavement LCCLCA model uses Carnegie Mellon University's Economic Input-Output Life Cycle Assessment tool (EIO-LCA) (CMUGDI, 2010). This tool utilizes the Leontief's methodology to relate the inter-sector monetary transactions sectors in the US economy, compiled in a set of matrices by the Bureau of Economic Analysis (BEA) of the US Department of Commerce, with a set of environmental indicators (e.g. consumption of fossil energy, airborne emissions, etc.) per monetary output of each industry sector of the economy. The environmental burdens at sector level associated with a particular commodity under analysis is therefore calculated by multiplying its monetary value, previously adjusted to US dollars of the EIO-LCA model's year according to sector-specific economic indices from the US Department of Labor, by the respective sectorial environmental multipliers obtained from the EIO-LCA model. 
The US 2002 EIO-LCA benchmark consumer price model for the US economy was preferred to the producer model because the monetary quantities of the commodities whose environmental burdens the study aims to quantify are better represented by retail price (e.g. construction equipment acquisition, tires acquisition, lubricating oil acquisition, etc.), which allows for further accounting of the environmental impacts associated with their distribution to wholesalers.

\subsection{Goal of the study}

The main goal of this study is to quantify and compare the life cycle environmental and economic performances of multiple pavement construction and maintenance practices that hold the potential for improving the environmental and economic dimensions of pavement sustainability. To this end, several scenarios involving the construction, maintenance and rehabilitation (M\&R) of a flexible road pavement section in Virginia, USA, were analyzed. The scenarios include the use of hot in-plant recycling mixtures, Sasobit ${ }^{\mathbb{B}}$ WMA, CCPR and preventive treatments.

The application of the pavement LCC-LCA model to the case study presented in this paper will advance the state-of-the-art by:

1) comprehensively estimating the potential environmental and economic advantages resulting from applying, individually or combined, new pavement engineering solutions instead of conventional materials and construction and M\&R methods;

2) demonstrating an integrated methodology that enables the inclusion of environmental loads and costs originated by processes and pavement LCA phases typically excluded from the system boundaries of pavement life cycle modeling approaches;

3) identifying the compromise solutions that best suit the often conflicting interests of the multiple stakeholders involved in the decision making process in the pavement management;

4) concluding how robust the suitability of the obtained compromise solutions are, when all ranges of combination of weights assigned to the criteria representing the stakeholder's perspectives are taken into account, as opposed to considering only a few sets of weights.

The results will provide an audience consisting of designers, contractors, local and state agencies and road users with an improved understanding of how materials considerations, treatment typology, design, construction, and application timing promise to enhance pavement sustainability while considering the tradeoffs between the requirements imposed by these players.

\subsection{Scope of the study}

The integrated pavement LCC-LCA model developed to carry out this study follows a cradle-to-grave approach, and consists in a parallel application of the LCA methodology taking into account, as far as possible and suitable, the guidelines provided by the International Standard Organization (ISO, 2006a,b) and the University of California Pavement Research Center's (UCPRC's) Pavement LCA Guideline (Harvey et al., 2010) and the LCC methodology based on the Swarr et al. (2011).

\subsubsection{Functional unit}

The functional unit considered in this case study for achieving these goals was defined as a $1 \mathrm{~km}$ long one-way road pavement section of an Interstate highway in Virginia, USA, with 2 lanes, each of which is $3.66 \mathrm{~m}$ wide. The project analysis period (PAP) was 50 years, beginning in 2011 with the construction of the pavement structure. The annual average daily traffic (AADT) for the first year was 20,000 vehicles of which $25 \%$ were trucks (5\% of the truck traffic consisted of single-unit trucks and the remaining percentage of combination trucks). The traffic growth rate was set equal to $3 \%$ per year.

\subsubsection{Product system- the initial pavement structure}




\subsubsection{Initial pavement structure design}

The initial pavement structure was designed using the pavement structural design method AASHTO'93 (AASHTO, 1993) for flexible pavements, as defined by the Chapter V-Pavement Evaluation and Design of the Virginia Department of Transportation (VDOT)'s Manual of Instructions for the Materials Division (VDOT, 2014). The assumptions considered during the design process are presented in Table 1.1 of the electronic supplementary materials. Based on the assumptions listed in that Table a pavement structure was designed with a structural number (SN) of 7.38. The details of the interstate flexible pavement structure and hot mix asphalt (HMA) mixtures properties are described in Table 1.2 of the electronic supplementary materials.

\subsubsection{Maintenance and rehabilitation scenarios}

This study analyzed and compared the environmental and economic performance of three main groups of alternative M\&R strategies (scenarios) applied over the PAP of the pavement structure presented in the previous section. The first two groups were based on the M\&R plan outlined by VDOT (VDOT, 2014), in which functional and structural treatments and a major rehabilitation are applied in preestablished years. Nevertheless, they were considered to differ from each other to the extent that in the first group only conventional asphalt materials and treatments were implemented, while in the second group the major rehabilitation was carried out through the combination of an in-place recycling technique, namely CCPR, and conventional asphalt layers. The recycling-based M\&R activity was designed in such a way that it provides equivalent structural capacity to non-recycling-based one and takes into account the VDOT's surface layers requirements for layers placed over recycling-based layers (VDOT, 2013). In turn, the third group consisted of preventive maintenance strategies.

The first two groups of alternative M\&R strategies, hereafter named VDOT strategy and Recycling-based VDOT strategy, respectively, were further divided into HMA and Sasobit ${ }^{\circledR}$ WMA scenarios with three distinct RAP contents ( $0 \%, 15 \%$ and $30 \%)$. As for the preventive alternative maintenance strategies, two additional scenarios were considered depending on the type of preventive treatments adopted: microsurfacing and thin hot mix asphalt overlay concrete (THMACO). A summary of the names of all considered scenarios is given in Table 1. Details on the M\&R activities and M\&R actions considered in the several M\&R scenarios are presented in Table 2.1 of the electronic supplementary materials. Table 2 presents the M\&R activities considered in each M\&R scenario, and respective application years.

Table 1. Identification of the alternative M\&R scenarios.

\begin{tabular}{ccl}
\hline Type of scenario & Scenario ID & \multicolumn{1}{c}{ Scenario name } \\
\hline \multirow{2}{*}{ VDOT } & 1 & HMA - 0\% RAP \\
& 3 & HMA - 15\% RAP \\
& 4 & HMA - 30\% RAP \\
& 5 & Sasobit ${ }^{\circledR}$ WMA - 0\% RAP \\
& 6 & Sasobit ${ }^{\circledR}$ WMA - 15\% RAP \\
& 7 & Sasobit ${ }^{\circledR}$ WMA - 30\% RAP \\
\hline \multirow{2}{*}{ Recycling-based VDOT } & 8 & HMA - 15\% RAP \\
& 9 & HMA - 30\% RAP \\
& 10 & Sasobit ${ }^{\circledR}$ WMA - 0\% RAP \\
& 11 & Sasobit \\
& 12 & SMA - 15\% RAP \\
Preventive maintenance & 13 & Microsurfacing - 0\% RAP \\
& 14 & THMACO - 0\% RAP \\
\hline
\end{tabular}


Table 2. M\&R activities considered in each M\&R scenario, and respective application years.

\begin{tabular}{lllllll}
\hline M\&R & M\&R activity ID & & & & 6 \\
\cline { 2 - 7 } scenario ID & 1 & 2 & 3 & 4 & 5 & - \\
\hline 1 to 6 & 12,44 & 22 & 32 & - & - & - \\
7 to 12 & 12,44 & 22 & - & 32 & - & \\
13 & $9,17,25,41,49$ & - & 32 & - & $7,15,23,39,47$ & \\
14 & $10,18,27,41,50$ & - & 32 & - & - & $7,16,24,39,47$ \\
\hline
\end{tabular}

In order to determine the pavement performance over time, the VDOT's pavement performance prediction models (PPPM) were used. VDOT developed a set of PPPM in units of CCI as a function of time and category of the last M\&R activity applied. CCI stands for Critical Condition Index and is an aggregated indicator ranging from 0 (complete failure) to 100 (perfect pavement) that represents the worst of either load-related or non-load-related distresses. Regarding the typologies of M\&R activities, VDOT classifies them into five categories: (0) Do Nothing (DN), (1) Preventative Maintenance (PM), (2) Corrective Maintenance (CM), (3) Restorative Maintenance (RM), and (4) Reconstruction/Rehabilitation (RC). Using the base form corresponding to Equation (1), VDOT defines PPPM for the last three categories (Stantec Consulting Services and Lochner, 2007). The coefficients of VDOT's load-related PPPM expressed through the Equation (1) for asphalt pavements of Interstate highways are presented in Table 3 (Stantec Consulting Services and Lochner, 2007).

,$C C I(t)=C C I_{0}-e^{a+b \times c} \ln \left(\frac{1}{t}\right)$

where $\operatorname{CCI}(t)$ is the critical condition index in year $t$ since the last M\&R activity, i.e. CM, RM or RC; $C C I_{0}$ is the critical condition index immediately after treatment; and $a, b$, and $c$ are the load-related PPPM coefficients (Table 3).

Table 3. Coefficients of VDOT's load-related PPPM expressed by the Equation (1) for asphalt pavements of interstate highways.

\begin{tabular}{ccccc}
\hline M\&R activity category & $C C I_{0}$ & $a$ & $b$ & $c$ \\
\hline CM & 100 & 9.176 & 9.18 & 1.27295 \\
RM & 100 & 9.176 & 9.18 & 1.25062 \\
RC & 100 & 9.176 & 9.18 & 1.22777 \\
\hline
\end{tabular}

Contrary to the remaining categories, VDOT did not develop individual PPPM for PM treatments. Thus, in this case study the considered PM treatments, i.e. microsurfacing and THMACO, were respectively modelled as a 8-point and 15-point improvement in the CCI of a road segment which take place whenever the CCI falls below the trigger value of 85 (Chowdhury, 2011). Once the treatment is applied, it is assumed that the pavement deteriorates according to the PPPM of a CM, without reduction of the effective age. On the other hand, in the case of the application of CM, RM and RC treatments, the CCI is brought to the condition of a brand new pavement (CCI equal to 100) and the age is restored to 0 regardless of the CCI value prior to the M\&R activity application.

For the purpose of estimating the environmental impacts and costs incurred by road users during the pavement usage phase due to the vehicles travelling over a rough pavement surface, a linear roughness prediction model, expressed in terms of International Roughness Index (IRI), was considered (Equation (2)). 


$$
, \operatorname{IRI}(t)=I R I_{0}+I R I_{g r w} \times t
$$

1

where $\operatorname{IRI}(t)$ is the IRI value $(\mathrm{m} / \mathrm{km})$ in year $t, I R I_{0}$ is the IRI immediately after the application of a given M\&R activity and $I R I_{\text {grw }}$ is the IRI growth rate throughout time, which was set at $0.08 \mathrm{~m} / \mathrm{km}$ (Bryce et al., 2014). It was assumed that the application of a M\&R activity other than PM restore the IRI to the value of a brand new pavement (IRI equal to $0.87 \mathrm{~m} / \mathrm{km}$ ). The IRI reduction due to the application of a PM treatment was determined based on the expected treatment life and assuming that there is no change in the $I R I_{g r w}$ value after the PM application (the same assumption was also made in the case of the remaining M\&R activities). Thus, by assuming treatment life periods of 3 and 5 years (Chowdhury, 2011), respectively for microsurfacing and THMACO preventive treatments, reductions in the IRI value of 0.24 and $0.40 \mathrm{~m} / \mathrm{km}$ were obtained.

Figure 1 shows the variation of the IRI over the PAP resulting from the implementation of the alternative M\&R scenarios. One can see that the pavement deterioration pattern corresponding to M\&R scenarios 1 to 12 is the same. Such an outcome is the consequence of taking as premise the fact that all mixtures perform in the same way throughout the PAP.

Insert Figure 1 approximately here.

\subsubsection{System boundaries, system processes, life cycle inventory data and main assumptions}

Figure 2 presents the phases and components included within the system boundaries of the proposed pavement LCC-LCA model as well as the relationships between the economic and environmental LCI. The model entails six pavement life cycle phases: (1) materials extraction and production, (2) construction and M\&R, (3) transportation of materials, (4) WZ traffic management, (5) usage, and (6) EOL. These phases were broken down into multiple components for each life cycle phase.

The environmental burdens and costs of planning, research, design activities, purchase of necessary rights-of-way, relocating utilities, constructing the roadway cuts and fills, and placing major drainage features for the mainline were not included into the system boundaries since the majority of those items regards to the whole road infrastructure and are either not exclusive to the pavement structure or entail a high level of subjectivity. Also excluded from the system boundaries were the environmental burdens due to labor. Furthermore, with regard to economic modelling performance, only real monetary flows were accounted for in order to avoid double counting the environmental impacts (Swarr et al., 2011).

The various models evoked while modelling each component of the pavement life cycle phases, as well as the main data required to run those models, are introduced and discussed in the following sections. Further details on the P-LCA modelling considerations can be found in Santos et al. (2015c). Detailed inventory data and complementary assumptions performed throughout the model application are shown in the electronic supplementary materials.

Insert Figure 2 approximately here.

\subsubsection{Environmental dimension}

4.3.3.1.1 Materials extraction and production phase

This pavement LCA phase addresses the environmental burdens arising from the acquisition and processing of the materials applied during the initial construction and future M\&R of a road pavement segment. This includes all materials manufacturing processes, from extraction of raw materials to their 
1 transformation into a pavement input material (material extraction sub-phase), ending with the mixture

\subsection{Materials extraction sub- phase} study for modelling the LCI of the following materials: fine and coarse aggregates (Stripple, 2001), bitumen and asphalt emulsion (Eurobitume, 2011), and tap water (Weidema et al., 2013). On the other hand, the LCI data for the following materials was obtained through the I-O LCI approach: hydrated lime, SBR, WMA additive $\left(\right.$ Sasobit $\left.^{\circledR}\right)$. Information about the economic sectors responsible for manufacturing the previously mentioned materials are presented in Table 3.1.1 of the electronic supplementary materials.

As far as the system boundaries for RAP are concerned, it is assumed that prior to its utilization the material is processed via a crushing operation, which reduces the variable RAP fragments to uniform size in order to promote final blend consistency. The environmental burdens resulting from milling or removing the previous pavement and hauling the recycled materials from the work site to the recycling unit were not included into the system boundaries on the basis of a 'cut-off' allocation criterion. Thus, only the post-processing of these materials is considered.

To accomplish the RAP processing task, a crusher unit located within the asphalt plant facility is considered, which consists of diesel-powered crusher (model Cone LS1200 from Kolberg-Pioneer, Inc.), a diesel-powered mobile screening plant (model FNG 2612D from Kolberg-Pioneer, Inc.), an electrically-powered stackable conveyor (model 47-3050S from Kolberg-Pioneer, Inc.) and a wheel loader (model 924HZ from Caterpillar). Based on the technical features of the equipment, a RAP processing capacity of 184 tons per hour was considered. The environmental burdens from processing RAP are those resulting from the operation of the engines and were obtained by applying the methodology adopted by the United States Environmental Protection Agency's (US EPA's) NONROAD 2008 model (US EPA, 2010a). However, the crusher units also emit fugitive particulate matter (PM) when processing RAP. The total emissions of fugitive PM released when crushing and screening RAP were determined from the Crushed Stone Processing and Pulverized Mineral Processing section of the U.S. EPA's AP-42: Compilation of Air Pollutant Emission Factors (US EPA, 2004).

\subsection{Materials production sub- phase}

This section addresses the LCI of the asphalt production process by considering different types of mixes, both with and without different RAP content. In this case study it was assumed that all asphalt mixes were produced through a natural gas-fired conventional drum-mix plant. In a conventional drum mix plant, RAP is not heated directly to prevent additional aging of RAP binder. Instead, the virgin aggregates are previously superheated so that when the RAP is introduced into the drum they dry and heat the RAP by conduction. However, such a superheating temperature is likely to cause additional energy consumption, which may eventually offset the economic and environmental benefits associated with the use of RAP.

In order to capture these tradeoffs along with the sensitivity of the air emissions due to the variations in composition and manufacturing temperature of the mixes and the moisture content of the 


$$
Q=\frac{\sum_{i=0}^{M} m_{i} \times \int_{T_{0 i}}^{T_{f i}} C_{i}(T) d T+L_{v} \times\left(m_{w v f}-m_{w v o}\right)}{\text { HeatingEffF }}
$$

raw materials, the heat energy required to produce the asphalt mixes was determined through an energy balance represented by Equation (3).
4

where $Q$ is the heat energy required to produce the asphalt mixture $(J), m_{i}$ is the mass of material $i$ $(\mathrm{kg}), M$ is the total number of materials, including water, $T_{f i}$ is the final temperature of material $i\left({ }^{\circ} \mathrm{C}\right)$, $T_{o i}$ is the initial temperature of material $i\left({ }^{\circ} \mathrm{C}\right), c_{i}(T)$ is the specific heat capacity coefficient, as a function of temperature, of material $i\left[\mathrm{~J} /\left(\mathrm{kg} /{ }^{\circ} \mathrm{C}\right)\right], L_{v}$ is the latent heat required to evaporate water (2256 $\mathrm{J} / \mathrm{kg}), m_{w v f}$ is the final mass of water vapor $(\mathrm{kg}), m_{w v_{o}}$ is the initial mass of water vapor $(\mathrm{kg})$, and HeatingEffF is a factor that represents the casing losses.

To account for the fact that specific heat capacities of minerals and fluids increase substantially with temperature, the equations presented by Waples and Waples (2004a,b) were adopted, taking the temperature of $20^{\circ} \mathrm{C}$ as the reference temperature. The heating requirements for the aggregates applied in bound layers other than surface layers were modeled by considering the specific heat value of limestone $\left[880 \mathrm{~J} /\left(\mathrm{kg} /{ }^{\circ} \mathrm{C}\right)\right]$. In the case of the surface layers, the value for quartzite $\left[1013 \mathrm{~J} /\left(\mathrm{kg} /{ }^{\circ} \mathrm{C}\right)\right]$ and diabase $\left[860 \mathrm{~J} /\left(\mathrm{kg} /{ }^{\circ} \mathrm{C}\right)\right]$ were taken to represent the aggregated used in the SM-type mixes and THMACO, respectively. With regard to binder and water, the third equation proposed by Gambill (1957) and the equation developed by Somerton (1992), both cited and displayed in Waples and Waples (2004b), were adopted, respectively. The initial moisture content of fine and coarse aggregates were assumed to be $3 \%$ and $1 \%$ (Harder, 2008), whereas for RAP a value of $4 \%$ was considered. As for the HeatingEffF, a value of $80 \%$ was adopted for the production of all mix types after calibrating the model with the data corresponding to the HMA production in the case study of Munster, Indiana, reported by West et al. (2014). The HMA mixing temperature was set at $160^{\circ} \mathrm{C}$ (APEC, 2000) and the initial temperature of all raw materials other than bitumen was assumed to be equal to the ambient temperature of $15^{\circ} \mathrm{C}$. In the case of the latter, it was considered that it remains stored at $160^{\circ} \mathrm{C}$ in heated tanks located in the asphalt plant facility. The volume of natural gas required to heat the insulated storage tanks was calculated based on the total quantity of binder heated, the total time the bitumen spends in the tanks throughout the paving season and the heat capacity of the tanks (see Table 3.1.2, Table 3.1.3 and Table 3.1.4 in electronic supplementary materials). As for the WMA, whose mix design was considered the same as that of the homologous HMA, it was assumed that the addition of $1.5 \%$ of Sasobit ${ }^{\circledR}$ per mass of bitumen reduces the mixing temperature by $25^{\circ} \mathrm{C}$ in relation to the reference temperature of $160^{\circ} \mathrm{C}$. This assumption was based on the range values of reduction of temperature of $20-30^{\circ} \mathrm{C}$ commonly referred to in the literature (D’Angelo et al., 2008; Rubio et al., 2012; Zhao and Guo, 2012). Moreover, it was also assumed that the RAP used in WMA can be blended with new asphalt binder at this lower temperature.

In order to determine the air emissions resulting from the mixing process of all mixes considered in this case study, a methodology was developed based on the emission factors (EFs) published by the AP-42 study of hot-mix asphalt (HMA) plants (US EPA, 2004) corresponding to a natural gas-fired filter-controlled drum-mix plan, and the thermal energy required to produce the asphalt mixes. Firstly, the average EFs referring to the production of a HMA with 0\% RAP were taken as reference. Secondly, as the $\mathrm{CO}_{2}$ emissions primarily result from fuel combustion, the average emission of this GHG was 
1 combined with the fuel emission coefficient (53.1 Kg/MMBtu) reported by United Sates Energy 2 Information Agency (EIA) to determine the quantity of natural gas whose combustion would release 3 the same amount of $\mathrm{CO}_{2}$ (US EIA, 2013). Thirdly, for each mix an EF multiplier was determined 4 through the ratio between the thermal energy computed with Equation (3) and the thermal energy 5 calculated according to the procedures previously described. Finally, GHG and air pollutant EFs from 6 mixes production were derived by multiplying the EFs taken as reference by the EF multipliers. The 7 values of the EF multipliers as well as the natural gas consumption requirements for producing all mixes 8 considered in this case study are shown in Table 4. The natural gas consumption reported in this table 9 was complemented with the consumption of electricity to account for the operation of the electric 10 components of the asphalt plant setup, e.g. conveyor, screens, etc. (Stripple, 2001).

Table 4. Natural gas consumption requirements for producing the asphalt mixes and EF multiplier values.

\begin{tabular}{|c|c|c|c|c|c|}
\hline \multirow{2}{*}{ Type of mix } & \multicolumn{2}{|c|}{ Natural gas consumption $^{\mathrm{a}}$} & \multirow[b]{2}{*}{ EF multiplier } & \multicolumn{2}{|c|}{ Natural gas consumption $^{\mathrm{b}}$} \\
\hline & $\mathrm{MJ}$ & $\mathrm{m}^{3}$ & & $\mathrm{MJ}$ & $\mathrm{m}^{3}$ \\
\hline Reference mix & 247 & 6.74 & 1 & - & - \\
\hline HMA: BM - 25.0 D, 0\% RAP & 217 & 5.93 & 0.880 & 225 & 6.15 \\
\hline HMA: IM - 19.0 D, 0\% RAP & 219 & 5.99 & 0.888 & 228 & 6.23 \\
\hline HMA: SM - 12.5 D, 0\% RAP & 245 & 6.69 & 0.992 & 254 & 6.94 \\
\hline THMACO & 218 & 5.95 & 0.882 & 226 & 6.18 \\
\hline HMA: BM - 25.0 D, 15\% RAP & 229 & 6.26 & 0.929 & 236 & 6.44 \\
\hline HMA: IM - 19.0 D, 15\% RAP & 228 & 6.23 & 0.924 & 236 & 6.43 \\
\hline HMA: SM - 12.5 D, 15\% RAP & 254 & 6.93 & 1.028 & 262 & 7.16 \\
\hline HMA: BM - 25.0 D, 30\% RAP & 242 & 6.59 & 0.978 & 247 & 6.74 \\
\hline HMA: IM - 19.0 D, 30\% RAP & 244 & 6.65 & 0.987 & 250 & 6.82 \\
\hline HMA: SM - 12.5 D, 30\% RAP & 270 & 7.36 & 1.091 & 276 & 7.55 \\
\hline WMA: BM - 25.0 D, 0\% RAP & 181 & 4.94 & 0.733 & 189 & 5.15 \\
\hline WMA: IM - 19.0 D, 0\% RAP & 183 & 4.99 & 0.740 & 191 & 5.22 \\
\hline WMA: SM - 12.5 D, 0\% RAP & 203 & 5.55 & 0.823 & 213 & 5.81 \\
\hline WMA: BM - 25.0 D, 15\% RAP & 193 & 5.27 & 0.781 & 199 & 5.45 \\
\hline WMA: IM - 19.0 D, 15\% RAP & 195 & 5.32 & 0.788 & 202 & 5.52 \\
\hline WMA: SM - 12.5 D, 15\% RAP & 215 & 5.88 & 0.872 & 224 & 6.11 \\
\hline WMA: BM - 25.0 D, 30\% RAP & 205 & 5.60 & 0.830 & 210 & 5.74 \\
\hline WMA: IM - 19.0 D, 30\% RAP & 207 & 5.65 & 0.837 & 213 & 5.81 \\
\hline WMA: SM - 12.5 D, 30\% RAP & 228 & 6.21 & 0.921 & 235 & 6.40 \\
\hline
\end{tabular}

${ }^{\mathrm{a}}$ It does not include the requirements for heating the insulated bitumen storage tanks.

b It includes the requirements for heating the insulated bitumen storage tanks.

Emissions and energy consumption due to the operation of the wheel loader at asphalt the plant facility were estimated based on the rate at which the wheel loader can move aggregates (Santos et al., 2015c) and the methodology adopted by the US EPA's NONROAD 2008 model (US EPA, 2010a).

In addition to the process-based components described throughout this section, the I-O LCI approach was adopted to estimate the environmental burdens associated with the manufacturing, repair, maintenance, interest on loan and insurance of the asphalt plant setup and auxiliary equipment (Table 3.1.1 of the electronic supplementary materials). The amortization of the environmental burdens was done by applying the portion of the asphalt plant setup and auxiliary equipment's depreciation that was actually allocated to the quantity of asphalt mixes consumed in a given construction activity and considering the average annual production of asphalt mixes. For example, if the annual depreciation of the asphalt plant setup is $\$ 150,000$, the average annual production of asphalt mixes in 2011 is 114,000 tonnes (Hansen and Copeland, 2014) and the quantity of asphalt mixes to be consumed in the construction activity is 1,000 tonnes, then $(150,000 / 114,000) \times 1,000=\$ 1,360$ is the economic value that will be input into the EIO-LCA model to determine the environmental burdens resulting from the manufacturing of asphalt plant that will be allocated to the construction activity considered. A similar 
1 approach was adopted in the construction, $M \& R$ and transportation of materials phases for determining 2 the environmental burdens associated with the construction equipment and hauling trucks, but taking 3 as allocation factors the number of usage hours and hauling kilometers travelled to undertake a given 4 construction activity.

\section{$5 \quad$ 4.3.3.1.2 Construction and M\&R phase}

6 In the construction and M\&R phase, the process-based environmental burdens are due to the 7 combustion-related emissions from construction equipment usage and were obtained by applying the 8 methodology adopted by the US EPA's NONROAD 2008 model (US EPA, 2010a). Information 9 regarding the type and features (e.g. brand, model, engine horsepower, etc.) of each equipment used to perform the several construction and M\&R activities, as well as their respective production rates were taken from the technical specifications provided by the equipment's manufacturers and complemented with the literature (US ACE, 2011; Caterpillar Inc., 2012).

In addition to the process-based components presented previously, the I-O LCI approach was adopted to estimate the environmental burdens associated with the equipment manufacturing, repair, maintenance, fuel, oil and greases (FOG) consumption, interest on loan, asset insurance, taxes on property, special wear items consumption and tire consumption of the equipment that define the construction or M\&R process being considered (Table 3.1.1 of the electronic supplementary materials).

In this section it is worth mentioning that the operating conditions of paving machines were considered the same, regardless of the type of asphalt mix considered, i.e. HMA or WMA. Although a reduction in the number of roller passes needed to achieve a specified density was theoretically expected due to the lower viscosity of WMA (Rubio et al., 2012; Zaumanis, 2014), there is no accurate and consistent scientific knowledge in the literature on the close relation between the reduction of the compactive effort required, in terms of roller passes, and the enhancement of WMA workability.

\subsection{Transportation of materials phase}

The process-based environmental impacts resulting from the materials and mixture transportation are due to the combustion process emissions released by the transportation vehicles. All materials and mixtures were assumed to be hauled by heavy-duty vehicles (HDVs). The US EPA's Motor Vehicle Emissions Simulator (MOVES) (US EPA, 2010b) was used to determine the average fuel consumption and airborne emissions factors for operating diesel powered, single unit short-haul trucks and long-haul combination trucks. The I-O LCI components considered in this pavement life cycle phase can be found in Table 3.1.1 of the electronic supplementary materials.

\subsection{WZ traffic management phase}

This pavement life cycle phase accounts for the fuel consumption and airborne emissions resulting from on-road vehicles traversing and detouring a work zone (WZ). It was assumed that whenever a WZ is in place, all vehicles will take a $10 \mathrm{~km}$ detour on a lower hierarchical level road at a speed $15 \mathrm{mph}$ lower than the normal operating speed of $70 \mathrm{mph}(112 \mathrm{~km} / \mathrm{h})$. The environmental burdens were calculated by adopting a process-based two-step method. First, the US EPA's MOVES model was run multiple times to compute a set of fuel consumption factors (FCFs) and airborne EFs on an hourly basis as a function of sixteen speed ranges. Second, the changes in traffic flow were estimated using the Highway Capacity Manual (HCM) 2000 (TRB, 2000) to determine several outputs, such as the number of vehicles that traversed the WZ, the average queue length, the average queue speed in each hour, etc. Once the changes in driving patterns were determined, they were combined with the FCFs and tailpipe vehicle Efs previously computed and stored in look up tables to derive the environmental load of a WZ day.

Finally, the marginal fuel consumption and airborne emissions due to the WZ traffic management plan were calculated by subtracting fuel consumption and airborne emissions released during a WZ 
1 period from the results of an equivalent non-WZ period. The same methodology was adopted to

2 calculate the I-O LCI components shown in Table 3.1.1 of the electronic supplementary materials.

$3 \quad$ 4.3.3.1.5 Usage phase

4 The usage phase addresses the pavement's environmental burden resulting from the interaction of the 5 pavement with the vehicles, environment and humans throughout its PAP. Among the factors that have 6 been identified in past research as being worthy of consideration during the usage phase of the pavement 7 (i.e. tire-pavement interaction, traffic flow, albedo, leachate and runoff, carbonation and lighting) only 8 the contribution from the tire-pavement interaction, namely the pavement roughness as measured by

9 IRI, was taken into account in this analysis. The rationale for this decision lies with the fact that the 10 remaining components either do not apply to the features of the case study under evaluation or lack well 11 established and consistent scientific background. In order to determine the influence of the pavement 12 roughness on vehicle FC and tailpipe emissions, the HDM-4 fuel consumption model (Bennett and 13 Greenwood, 2003), calibrated and validated for US conditions by Chatti and Zaabar (2012), was 14 combined with data from the US EPA's MOVES model according to the approach proposed by Santos et al. (2015c). In the particular case of the effect of the macrotexture on vehicle fuel economy, this was not considered because the prediction of its evolution over time is a difficult task, in the sense that it may present contradictory behaviours (i.e., increase or decrease over time) depending on the type of distresses developed throughout the pavement life cycle. The effects of this surface property on fuel consumption would have been considered if the research work described in this paper had been applied to a real pavement section with a record of macrotexture measurements that enabled the development of a prediction model. However, the pavement section considered in the case study is a generic section, representative of the conditions existing in a typical Interstate highway in Virginia.

As far as the I-O LCI components are concerned, the environmental burdens related to the following items were considered: on-road vehicles manufacturing, maintenance and repair and tire consumption (Table 3.1.1 of the electronic supplementary materials).

\subsection{End-of-life phase}

Given the hierarchical level of the road under consideration the most likely EOL scenario for the pavement section in this analysis is that it will remain in place after reaching the end of the PAP, serving as the foundation for the new pavement structure. Thus, in order to model this pavement life cycle phase a 'cut-off' allocation method was adopted. According to this allocation method, each product is assigned only the burdens directly associated with it (Nicholson, 2009). Therefore, no environmental burdens were assigned to the EOL phase of all alternative scenarios.

\subsection{Energy Production}

Although it is not considered a pavement life cycle phase, as are those previously introduced, energy source production and transportation is an unavoidable process that is common to all pavement life cycle phases. In this case study, the GREET model (Argonne National Laboratory, 2013) was used as the source of the LCI for the production and delivery of energy sources. For all energy sources except electricity, the GREET model default data was used. In the case of electricity, a default electricity mix was modified to reflect the electricity production in the state of Virginia (US EIA, 2012).

\subsubsection{Economic dimension}

\subsection{Materials extraction and production phase}

This phase accounts for the costs incurred by the highway agency in producing the mixtures to be applied during the construction and M\&R phases. Materials extraction and production phase costs were divided into three main categories: (1) raw materials costs, (2) energy sources costs and (3) asphalt plant operating costs. The last category was further divided into fixed and variable costs sub-categories. 
In this section, it should be mentioned that a change in the price of the virgin asphalt binder was considered when a RAP percentage of $30 \%$ was used in the mixes due to the lower PG category of the asphalt binder used in those circumstances (VDOT, 2012a).

\subsection{Construction and M\&R phase}

The construction and M\&R phase costs represent the costs incurred by the highway agency during the actual performance of a construction or M\&R activity at a particular work site on a specific day and time. They include the construction equipment owning costs (depreciation, interest, insurance, taxes on property and allocation to work site), the construction equipment operation costs (fuel consumption, planned maintenance and FOG, repair, tire consumption and special wear items) and the labor costs corresponding to the wages and benefits paid to the crew members for the work performed at a work place. The materials costs, as well as the costs associated with the hauling movements required to deliver the materials from the point of production to their destinations are accounted for in individual phases. Data required for computing the various subcategories of construction equipment owning and operating costs were collected for each piece of equipment according to the information made available by equipment manufacturers, suppliers and dealers, or existing in the literature (US ACE, 2011; Caterpillar Inc., 2012). The number of workers needed to carry out the several M\&R actions for a given M\&R activity was estimated according to data gathered in the field during visits to similar recycling projects, or existing in the literature (EAPA and NAPA, 2011).

\subsection{Transportation of materials phase} The theoretical economic advantage of recycling-based construction and M\&R practices is strongly affected by material transportation costs and how those costs compare to the cost of new virgin materials delivered to the construction site. Thus, unlike the majority of the LCC models existing in the literature, the proposed LCC model presents the costs incurred by the highway agencies due to the transportation of the materials separated out from the remaining categories that constitute the total delivery price.

As with construction and M\&R phase costs, three main cost categories were considered: (1) hauling trucks owning costs (depreciation, interest, insurance and taxes on property), (2) hauling trucks operation costs (fuel consumption, planned maintenance and FOG, repair, tire consumption and special wear items) and (3) labor costs (hauling truck drivers’ wages and benefits).

\subsection{WZ traffic management phase}

30 The WZ traffic management costs consist of the additional costs borne by the road users (RUC) when facing a disruption of the normal traffic flow as a consequence of the constraints imposed by a WZ traffic management plan. In this LCC model the following WZ traffic management costs categories were considered: (1) time delay costs (TDC) and (2) vehicle operating costs (VOC). Accident costs, typically considered as another WZ RUC category, were disregarded due to the high level of uncertainty associated with the factors that might determine their occurrence (which are often related with driver errors and other factors not related with the WZ).

\subsection{Usage phase}

38 The usage phase costs, frequently named non-WZ RUC, account for the marginal VOCs supported by the vehicle drivers throughout the PAP as a consequence of the deterioration of the pavement condition. In the proposed LCC sub-model, the pavement roughness, as measured by the IRI, was used to estimate the RUC associated with the overall pavement surface condition. The following costs categories were considered to be contributors to the total usage phase costs: (1) fuel consumption, (2) tire wear, (3) vehicle maintenance and repair and (4) mileage-related vehicle depreciation. The first three costs 
1 effect of the pavement roughness on vehicle depreciation costs was determined according to the

2 methodology presented by Barnes and Langworthy (2003).

\subsection{End-of-life phase}

In the case study, the most likely EOL scenario for the analyzed pavement structure is that it will remain in place after reaching the end of the PAP, serving as the foundation for the new pavement structure. Thus, the salvage value of the pavement structure is given by the value of its remaining service life. The service life of the pavement was assumed to end when the CCI exceeds the value of 49, which according to the VDOT's Highway System Performance Dashboard (VDOT, 2012b) corresponds to the threshold ( $C C I_{\text {Terminal }}$ ) beyond which a ride is classified as "very poor".

In order to compute the value of the remaining service life, and thus, the salvage value of the pavement at end of the PAP, Equation (4) was adopted. It quantifies the salvage value of the pavement as the proportion of the total highway agency costs incurred due to the application of the last M\&R activity equal to the proportion of the remaining life of that M\&R activity (Walls and Smith, 1998).

$$
, C_{E O L \text { phase }}=C_{\text {Last M\&Ractivity }} \times \frac{C C I_{E O L}-C C I_{\text {Terminal }}}{100-C C I_{\text {Terminal }}}
$$

15

where $C_{\text {Last M\&Ractivity }}$ is the total highway agency cost resulting from the application of the last M\&R activity. It is obtained by summing up the costs incurred by the highway agency during the materials, M\&R and transportation of materials phases associated with the last M\&R activity; $C C I_{E O L}$ is the CCI of the pavement at the end of the PAP; and $C C I_{\text {Terminal }}$ is the CCI value beyond which a ride is classified as "very poor".

\subsection{Life cycle impacts assessment}

The US-based impact assessment methodology, the Tool for the Reduction and Assessment of Chemical and other environmental Impacts 2.0 - TRACI 2.0 (Bare et al., 2011) from the US EPA, was adopted in this study to conduct the impact assessment step of the LCA on the basis of obtained inventory as compiled in the previous step. The TRACI impact categories used in the analysis include: acidification air (AC), eutrophication air (EU), human health criteria pollutants (HH) and photochemical smog formation (PSF). The time-adjusted characterization model for the climate change (CC) impact category that was proposed by Kendall (2012) was used, as opposed to the traditional timesteady International Panel on Climate Change model. Furthermore, three energy-based indicators were also included in the assessment: (1) primary energy obtained from fossil resources, (2) primary energy obtained from non-fossil resources and (3) feedstock energy. The feedstock energy was fully allocated to the virgin binder, with none attributed to RAP. This assumption aims to avoid double counting since it would be expected to be accounted for in the previous pavement system.

\subsection{Life cycle costs computation}

Once all the cost categories associated with each scenario under assessment are identified and calculated, the concept of net present value (NPV) was applied. This allows expenses occurring at different points in time to be summed up on a yearly basis by using a discount rate in the calculations to reflect the "time value of money". In this case study, a real discount rate of $2.3 \%$ was used. It follows the Office of Management and Budget's (OMB's) guidelines for conducting benefit-cost of federal programs with durations of longer than 30 years for the calendar year of 2011 (OMB, 2013). 


\section{5. Results and discussion}

\section{5.1. Life cycle impact assessment}

3 Figures 3(a) to 3(h) display the normalized life cycle impacts of the alternative scenarios across the 4 eight impact and energy demand categories. Each scenario is normalized by the impact category score observed in the first scenario, where all conventional materials and M\&R activities were applied. In addition, for each pavement life cycle phase, the relative savings in relation to the homologous phase of scenario 1 are presented. Complementarily, the absolute value of the impact category scores are illustrated with labels placed right below the top of the bars.

Insert Figure 3 approximately here.

These results clearly indicate that scenario 14 (preventive maintenance: THMACO) is the least harmful to the environment, as it was found to cause the lowest impact in seven out of eight impact and energy demand categories. Compared to scenario 1, a reduction in all impacts ranging from $18 \%(\mathrm{HH})$ to $38 \%$ (NFoPE), can be achieved as a result of implementing the THMACO-based preventive M\&R strategy. The second best environmental performance is denoted by the microsurfacing-based preventive M\&R scenario. The fact that the implementation of preventive M\&R strategies results in a better pavement condition throughout the PAP along with the key role played by the usage phase in driving the environmental performance of a pavement system, explains the greater reduction in the environmental impact associated with the implementation of scenarios 13 and 14.

Contrary to the merits exhibited by the preventive maintenance scenarios, the scenarios consisting of implementing the VDOT M\&R strategy present the highest environmental impact. In particular, scenario 4 (VDOT M\&R strategy: WMA - 0\% RAP) entails the highest environmental impact for four out of eight impact and energy demand categories. However, it is worth mentioning that this result should not be seen as conclusive with regard to the disadvantages of WMA over conventional mixtures, since the environmental burdens that scenario 4 originate are quite similar to those of the scenario 1 (VDOT M\&R strategy: HMA - 0\% RAP), and do not show a steady pattern of improvement or deterioration of the environmental performance across all impact categories. Moreover, scenario 1 entails the highest environmental impact for three out of eight impact and energy demand categories, and overall, it is the second most harmful scenario when scenario 4 presents the poorest environmental performance. For instance, examining the lines in Figure 3(b), which display the savings of emissions of $\mathrm{SO}_{2}$-eq incurred during the materials phases, one can see that the difference between the aforementioned scenarios is just $1.33 \%$. Residual savings are also observed in the remaining impact and energy demand categories. The exception is the NFoPE energy demand, where an improvement of the environmental performance was observed, which can be as high as $33.18 \%$. Such residual and contradictory values mean that for the conditions considered in this case study, the overall impacts of WMA are not substantially different from those of HMA with the same RAP content, and a general conclusion on which type of mix is environmentally preferable cannot be drawn. Therefore, one noteworthy outcome of this case study is that the decrease in the impacts of WMA due to the reduction of production temperature is offset by the increase in the impacts due to the production of Sasobit ${ }^{\circledR}$, despite its small proportion in mixture composition. Furthermore, even if the lower compacting efforts associated with the WMA were taken into account, there would be no meaningful change in the environmental performance of the system under analysis, as the environmental burdens associated with the operation of construction equipment have a relatively small impact over the life of a pavement.

Regarding the environmental benefits resulting from incorporating RAP into asphalt mixtures, the comparison of scenarios involving the application of the same type of mixture but with different RAP contents shows that the environmental impacts can be reduced by as much as $17 \%$ (AC due to materials 
phase), and 29\% (FsE). Overall, in relative terms, the greatest advantage stems from either the materials or the transportation of materials phases, while in absolute terms the materials phase plays the most important role in lowering the overall environmental impact.

As far as the potential environmental benefits of implementing recycling-based M\&R activities, as opposed to the conventional M\&R practices, are concerned, Figures 3(a) to 3(h) show considerable environmental impact reductions across all categories. The maximum reduction in environmental burden can be as high as $16 \%$ and was observed in the NFoPE energy demand of the materials phase. In absolute terms, the majority of the environmental benefits spring from materials and WZ traffic management phases, depending on the impact category being considered. Despite the overall benefits associated with the implementation of the recycling-based VDOT M\&R strategies (scenarios 7 to 12), it should be noted that the construction and M\&R phases of those scenarios present the poorest environmental performance among competing scenarios. The reason for this outcome lies with the fact that the implementation of recycling-based $M \& R$ activities requires the use of heavy construction equipment with high-rated power engines.

\subsection{Life cycle costs analysis}

Figures 4(a) shows the normalized life cycle highway agency costs corresponding to the alternative scenarios. Each scenario is normalized by the net life cycle highway agency cost observed in the first scenario. In addition, for each pavement life cycle phase, the relative savings in relation to the homologous phase of scenario 1 are presented. Complementarily, the absolute value of the net life cycle highway agency costs are illustrated with the labels placed right below the top of the bars.

Insert Figure 1 approximately here.

23

From the analysis of Figure 4(a), it can be seen that overall, the recycling-based VDOT M\&R scenarios are the most advantageous from the highway agency's perspective. Four out of six scenarios rank in the top six of the least expensive, with scenario 9 (recycling-based VDOT strategy: HMA - 30 $\%$ RAP), being the one that allows highway agencies the greatest life cycle savings. A reduction of approximately $24 \%$ of the net life cycle highway agency costs can be achieved if this scenario is implemented instead of the first one. The contributions to the reduction of the net life cycle highway agency costs for the scenario 9 come from the materials (30\%) and transportation of materials (24\%) phases. Despite the overall benefits resulting from implementing recycling-based VDOT scenarios, their construction and M\&R phases exhibit worse economic performances than the non-recycling-based counterparts. This is because undertaking recycling-based M\&R activities requires the use of heavy construction equipment which commonly incurs high owning and operating costs.

In contrast, the preventive maintenance scenarios are the least beneficial for the highway agency's interests, as they imply an increase in the life cycle costs of about 3 and 9\% in relation to scenario 1. These outcomes are explained by the greater number of interventions that are required to be implemented in order to comply with the M\&R triggering policy. Another outcome worth highlighting in Figure 4(a) concerns the third poorest performance, among all the competing alternatives, as seen in scenario 4 (VDOT M\&R strategy: Sasobit ${ }^{\circledR}$ WMA - 0\% RAP), as it implies a slight increase in the life cycle highway agency costs of about $2.2 \%$ in relation to scenario 1 . This result means that the benefits resulting from energy cost savings associated with the manufacturing of WMA were offset by the increased production costs related to the asphalt plant modifications, which in this case study, consisted of adding a pneumatic Sasobit ${ }^{\circledR}$ feeder to the default equipment existing in an asphalt plant facility, and the acquisition and transportation costs of the Sasobit ${ }^{\circledR}$. 
As for the costs incurred by road users, Figure 4(b) shows the normalized life cycle RUC. Analogously to Figure 4(a), each scenario is normalized by the road user life cycle cost observed in the first scenario. The relative savings in relation to the homologous phase of scenario 1 and the absolute value of the life cycle RUC, expressed in thousands of US dollars, are also presented in the same figure. Scenarios 7 to 12 (recycling-based VDOT M\&R scenarios), exhibit the lowest life cycle RUC among alternatives, with a value of approximately $\$ 2,978,166$. These scenarios are followed by the THMACObased scenario, which imposes on road users a life cycle cost of about $\$ 2,956,458$. On the other hand, the microsurfacing-based scenario implies the highest costs for road users, with a life cycle value of approximately $\$ 3,701,513$. Comparing the contribution given by each type of RUC, Figure 4(b) shows that the percentage of non-WZ RUC in the total value incurred by these stakeholders ranges from 15 to $33 \%$, with an average value of $31 \%$.

\subsection{Overall performance}

In order to determine the preference order of alternative scenarios, a MCDA method was applied. Specifically, the TOPSIS method (Hwang and Yoon, 1981), was chosen due to its (1) simple, rational and understandable concept; (2) straightforward computation; (3) ability to depict the relative performance of decision alternatives in a simple mathematical form (Anupam et al., 2014); and (4) broad recognition and application in the construction sector (Jato-Espino et al., 2014). Three main criteria were considered: HAC, RUC and environmental impacts. The last criterion was further broken down into 8 sub-criteria, each representing one environmental impact category.

Depending on policy makers' preferences, different weights can be assigned to each criterion. This is a challenging task since there are often multiple decision-makers with different agendas and biases towards their interests. To elucidate decision-makers on the consequences of the weighting in the ranking of the alternative scenarios, a combinatorial weight assignment method was undertaken for the main criteria, while the weights assigned to the environmental sub-criteria remained unchangeable and equal to those adopted by the US-based Building for Economic and Environmental Sustainability (BEES) software (Lippiatt, 2007). Since the energy demand indicators considered in the proposed LCCLCA model are not available in the BEES software, they were given a weight of 5 points each, as much as the weight assigned to the Fossil Fuel Depletion impact category considered in BEES software. All the weights assigned to the environmental sub-criteria were posteriorly rescaled, so that the sum of their values totals 100 points. Thus, in the MCDA, the final weight of each environmental sub-criterion is the value resulting from multiplying the weight of the main environmental criterion by the weight determined, as explained above.

The best scenario for all possible weighting combinations between the three main criteria is displayed in Figure 5 through a triangular diagram (Hofstetter et al., 1999; Graham and Midgley, 2000). The axes are scaled so they increase in a clockwise direction around the diagram. Each point in the triangle area corresponds to a specific weighting set and the relative weights always add up to a total weight of 1 (or $100 \%$ ). This leads to a graphical representation of two dominance areas separated by a straight equilibrium line. This line comprises a set of points in the triangle where the scenarios being compared have the same ranking position. From the analysis of Figure 5 one can conclude that of the competing scenarios, only two (scenarios 9 and 14) have the potential to rank best. Of those, scenario 9 is clearly the one that presents the largest area of superiority. If the decision is exclusively based on either HAC or RUC, scenario 9 ranks best. In turn, if the environmental performance is the only criterion taken into account, then scenario 14 outperforms the remaining ones. 


\subsection{Sensitivity and scenario analysis}

The economic and environmental assessment of new pavement engineering solutions was carried out on the basis that those solutions perform in the same way as their conventional counterparts with respect to IRI progression. Although this assumption finds support in several studies for some technologies (Sol-Sánchez et al., 2016; Mohammad et al., 2015), there are also other studies suggesting that some of those solutions may not perform as well as the conventional solutions (Modarres et al., 2014). Given the lack of results obtained from comprehensive field studies about the long-term performance of road pavements incorporating new pavement engineering solutions, it is pertinent to consider that new paving materials/solutions may not be as durable as the conventional materials. Furthermore, there is also literature arguing that in some cases, not all of the binder on the recycled aggregates will be mobilized (partial blending effects for RAP integration) (Shirodkar et al., 2013, 2011). In addition, the degree of blending may be lower in WMA due to lower mixing temperatures, but this effect is not fully known yet (Bowers et al., 2014; Gaitan et al., 2013). Therefore, the $100 \%$ assumption of activated RAP binder may result in underperforming under-asphalted mixture designs. Similarly, Sasobit ${ }^{\circledR}$ may change their design and increase the amount used in mixes. As such, the results presented in the previous sections are likely to be subject to some degree of uncertainty. Therefore, a sensitivity and scenario analysis were conducted to examine how variations across a set of parameters and assumptions affect the robustness of the reported outcomes, and thereby, the relative merits of the alternatives being considered and compared. In particular, the "One-(factor)-At-a-Time” (OAT) sensitivity analysis method was used. In this method, output variations are induced by varying one input factor at a time, while all others are held at their default values.

Table 5 presents the triangular diagrams that display the best scenarios for all possible weighting combinations between the three main criteria when each model parameter is individually changed $+60 \%$ with respect to the base scenario. For the sake of brevity, the corresponding normalized life cycle impacts, energy demand scores and component costs (highway agency and road user costs) are shown in the electronic supplementary materials (point 4).

From the analysis of Table 5 it is clear that the position of scenarios 9 and 14 in the ranking of the best compromise solutions is robust. In general, the consideration of scenarios different from the baseline only originate a slight change in the areas of dominance. The only exception to this outcome is observed when different IRI grow rates are considered. In these circumstances, for a given set of weights scenario 1 was found to be the best compromise scenario. This happens when the weight values assigned to the environmental sub-criteria are high while those assigned to the remaining criteria are low, and can be explained by the increase in the roughness-related user costs associated with higher IRI grow rates. 
Table 5. Results of the sensitivity and scenario analysis expressed in terms of the best M\&R scenarios for all possible weighting combinations of the main criteria.

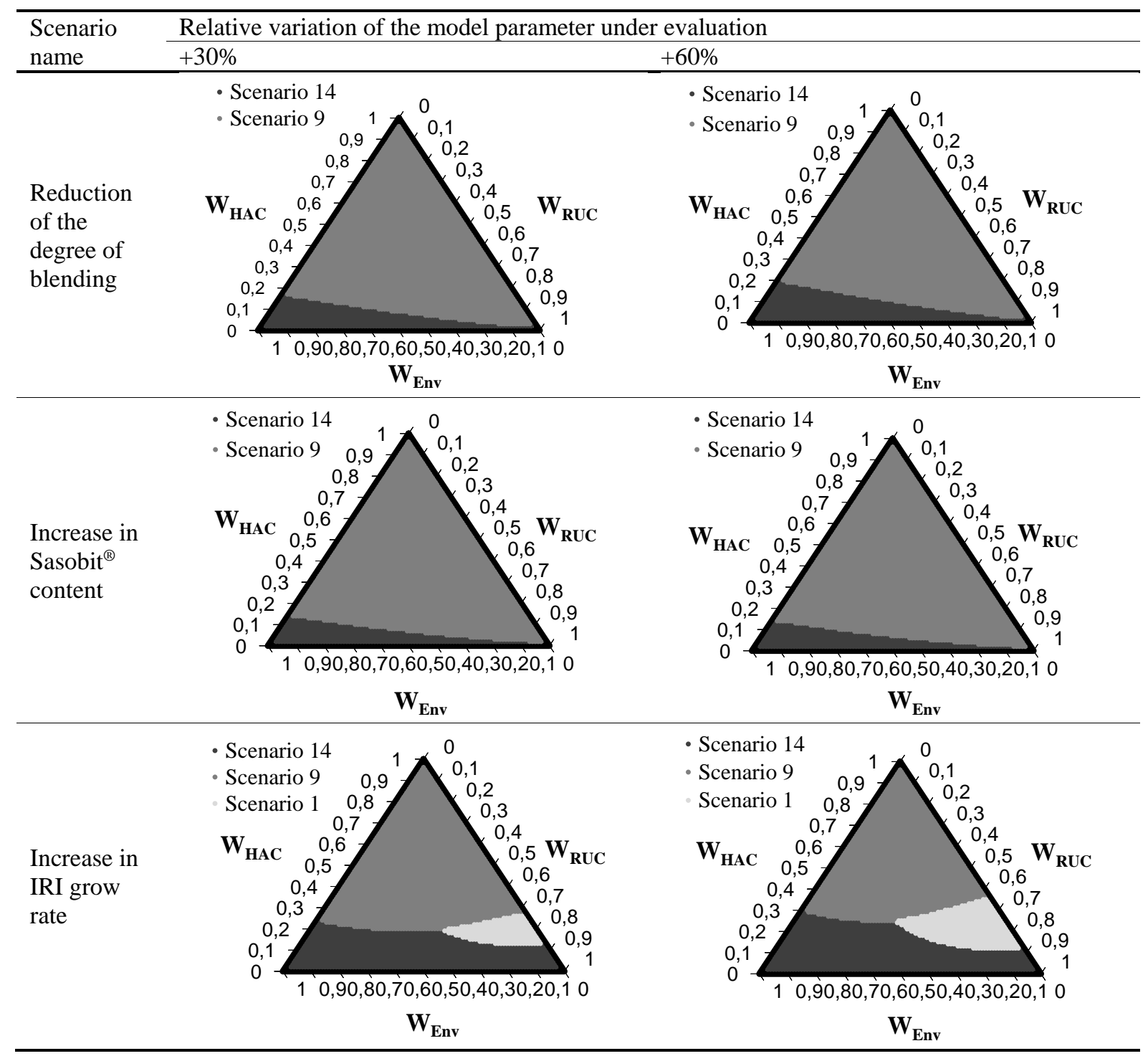

\subsection{Key findings}

From the methodology and results presented and discussed in the previous sections, the following findings are worth highlighting:

- THMACO-based preventive maintenance is the least harmful scenario to the environment, being responsible for the lowest impacts in the overwhelming majority of the categories. Compared to the scenario where only conventional materials and treatments are applied (scenario 1), a reduction in all impacts ranging from $18 \%(\mathrm{HH})$ to $38 \%$ (NFoPE) can be achieved as a result of implementing the THMACO-based preventive M\&R strategy;

- The life cycle environmental impacts of WMA are in general identical to those of HMA with the same RAP content. The decrease in the impacts of WMA due to the reduction of production temperature is offset by the increase in the impacts due to the production of Sasobit ${ }^{\circledR}$;

- Producing asphalt mixes with $30 \%$ of RAP allows environmental impacts to be reduced by as much as $29 \%$ (FsE impact category). In relative terms, the greatest advantage springs from the transportation of materials phase, while in absolute terms the materials phase plays the most important role in lowering the overall environmental impacts; 
- Applying a recycling-based VDOT M\&R strategy where the structural treatments is carried out through a CCPR technique leads to reduction in the environmental burdens of some pavement life cycle phases that can be as high as $16 \%$ in relation to those generated by an equivalent and conventional M\&R strategy;

- Applying the THMACO-based preventive M\&R strategy is simultaneously the most costly strategy for the highway agency and the least expensive for road users. On the other hand, implementing the recycling-based VDOT M\&R strategy, where the asphalt mixtures are of type HMA containing $30 \%$ of RAP (scenario 9), and the microsurfacing-based preventive M\&R strategy, yield the greatest life cycle highway agency savings and RUC expenses, respectively;

- The recycling-based VDOT M\&R strategy: HMA - 30 \% RAP is clearly the scenario that best suits the majority of the interests of the stakeholders as a whole, even when different design and performance scenarios of the mixtures and type of treatments are evaluated.

\section{Summary and conclusions}

A shift towards more environmentally and economically responsible behavior in the road pavement construction and management field triggered the need to develop and implement new pavement engineering solutions. Complementarily, a comprehensive and wide-scoped assessment of the effectiveness of those solutions in achieving their intended objectives, requires the use of comprehensive life cycle modelling approaches, which provide valuable information for those in charge of making decisions.

Keeping this in mind, a comprehensive and integrated pavement LCC-LCA model was developed and used to investigate the potential environmental and economic benefits resulting from applying inplant recycling mixtures, WMA, cold in-place recycling and preventive treatments throughout the life cycle of a pavement structure.

For the conditions considered in this case study, the recycling-based VDOT M\&R strategy, where the asphalt mixtures are of type HMA containing $30 \%$ of RAP has been shown to be more compliant with the highway agency and road users' demands for affordable road maintenance and usage over its life cycle than the remaining technical solutions investigated. Moreover, this solution also revealed a superior overall performance when the interests of all three stakeholders, meaning highway agency, highway users and the environment, were concomitantly taken into account in a MCDA. On the other hand, from the exclusive environmental performance point of view, implementing a THMACO-based preventive maintenance strategy has proven to be the most environmentally preferable solution.

A sensitivity and scenario analysis was undertaken to assess the robustness of the outcomes in response to variations in some of the most relevant input values. The analysis has shown that variances to the key assumptions considered when assessing the life-cycle environmental and economic performances of multiple pavement construction and maintenance practices do not considerably alter the overall advantage resulting from implementing a recycling-based VDOT M\&R strategy, where the asphalt mixtures are of type HMA containing $30 \%$ of RAP.

Providing life cycle perspectives of the environmental and economic implications of implementing new pavement engineering solutions and management practices is without doubt an essential first step towards enhancing pavement infrastructure sustainability. In this sense, because the methodology presented in this paper possesses a clear and well-defined mathematical formulation, it can easily be made available to asphalt mixtures producers and/or department of transportation engineers in a software tool. Its use in parallel with monitoring systems, which, among other tasks, controls aggregates and RAP moisture contents and mixing temperatures, can be useful to set thresholds beyond which an increase (or decrease) of the parameter values may have a negative impact on the economic and/or environmental performance of a given paving strategy, either for the particular conditions of the project in question or for the overall conditions of applicability of the pavement engineering solution. 
Furthermore, although it does not consider the social dimension of sustainability, the proposed methodology represents an additional step in helping decision makers to promote solutions that are expected to result in more sustainable pavements. Given that it relies on a comprehensive approach, it allows practices to be evaluated from a wider and more collective system perspective, which is beneficial for capturing the eventual existence of environmental and economic tradeoffs resulting from including commonly neglected substances and processes within the scope of analysis. Also, by displaying the best compromise alternatives corresponding to all combinations of weights, it provides a learning platform for those in charge of the decision-making process. In this way, they can directly evaluate how the final decisions vary depending on the preferences and perspectives of the multiple stakeholders.

Nevertheless, it is no less true that decision making in a pavement management context is a much more complex exercise, where other variables and constraints came into play, so it cannot be efficiently conducted through the exclusive use of LCA and LCC approaches. Improved approaches for optimizing the selection of treatments, materials and application timings based on specific and often conflicting objectives and constraints are required. Thus, future work on this topic will focus on enhancing the potentialities and capabilities of the proposed LCC-LCA model by integrating it into a multi-objective optimization framework.

\section{Acknowledgements and disclaimer}

This work has been supported by the project EMSURE - Energy and Mobility for Sustainable Regions (CENTRO-07-0224-FEDER-002004) and by the Transportation Pooled Fund TPF-5(268) National Sustainable Pavement Consortium. João Santos wishes to thank the Portuguese Foundation for Science and Technology for a personal research grant (SFRH/BD/79982/2011).

The contents of this paper reflect the views of the authors, who are responsible for the facts and the accuracy of the data presented. The contents do not necessarily reflect the official views or policies of the Virginia Department of Transportation, the Commonwealth Transportation Board or the Federal Highway Administration. Any inclusion of manufacturer names, trade names, or trademarks is for identification purposes only and is not to be considered an endorsement. Moreover, this paper does not constitute a standard, specification, or regulation.

\section{References}

American Association of State Highway and Transportation Officials (AASTO), 1993. Guide for design of pavement structures. 4th ed. Washington, DC: American Association of State Highway and Transportation Officials.

Anupam, K., Lal, P., Bist, V., Sharma, A. and Swaroop, V., 2014. Raw material selection for pulping and papermaking using TOPSIS multiple criteria decision making design. Environmental Progress \& Sustainable Energy, 33 (3), 1034-1041. doi:10.1002/ep.11851

Argonne National Laboratory, 2013. GREET life-cycle model user guide. Lemont, IL: Center for Transportation Research, Energy Systems Division, Argonne National Laboratory. Retrieved from http://greet.es.anl.gov/

Asphalt Pavement Environmental Council (APEC), 2000. Best management practices to minimize emissions during HMA construction. EC 101, National Asphalt Pavement Association, the Asphalt Institute, and the State Asphalt Pavement Associations.

Aurangzeb, Q., Al-Qadi, I., Ozer, H. and Yang, R., 2014. Hybrid life cycle assessment for asphalt mixtures with high RAP content. Resources, Conservation and Recycling, 83, 77-86. doi:10.1016/j.resconrec.2013.12.004 
Bare, J., 2011. TRACI 2.0: The tool for the reduction and assessment of chemical and other environmental impacts 2.0. Clean Technologies and Environmental Policy, 13 (5), 687-696. doi:10.1007/s10098-010-0338-9

Barnes, G. and Langworthy, P., 2003. The per-mile costs of operating automobiles and trucks. Report No. MN/RC 2003-19, University of Minnesota. Retrieved from: http://www.cts.umn.edu/publications/researchreports/reportdetail.html?id=670

Bennett, C., and Greenwood, I., 2003. Modeling road user and environmental effects in HDM-4, version 3.0, International Study of Highway Development and Management Tools (ISOHDM) (Vol. 7). Paris: World Road Association (PIARC). ISBN 2-84060-103-6.

Bilec, M., Ries, R., Mattews, S. and Sharrard, A., 2006. Examples of a hybrid life-cycle assessment of construction processes. ASCE-Journal of Infrastructure Systems, 12(4), 207-215. http://dx.doi.org/10.1061/(ASCE)1076-0342(2006)12:4(207)

Bilec, M., Ries, R., and Matthews, S., 2010. Life-cycle assessment modeling of construction processes for buildings. ASCE-Journal of Infrastructure Systems, 16(3), 199-205. http://dx.doi.org/10.1061/(ASCE)IS.1943-555X.0000022

Birgisdóttir, H., Pihl, K., Bhander, G., Hauschild, M. and Christensen, T., 2006. Environmental assessment of roads constructed with and without bottom ash from municipal solid waste incineration. Transportation Research Part D: Transport and Environment, 11 (5), 358-368. doi:10.1016/j.trd.2006.07.001

Bowers, B., Moore, J., Huang, B. and Shu, X., 2014. Blending efficiency of Reclaimed Asphalt Pavement: An approach utilizing rheological properties and molecular weight distributions. Fuel, 135, 63-68. doi:10.1016/j.fuel.2014.05.059.

British Columbia Road Builders and Heavy Construction Association (BCRB and HCA), 2011. Reducing greenhouse gas emissions in the B.C. road building and maintenance industry, Road building and highway maintenance best practice guidelines, British Columbia Ministry of Transportation and Infrastructure. Retrieved form: http://www.th.gov.bc.ca/publications/eng_publications/geotech/3348_Roadbuilding_BP-V13232ppi.pdf

Bryce, J., Flintsch, G. and Hall, R., 2014. A multi criteria decision analysis technique for including environmental impacts in sustainable infrastructure management business practices. Transportation Research Part D: Transport and Environment, 32, 435-445. doi:10.1016/j.trd.2014.08.019

Carnegie Mellon University Green Design Institute (CMUGDI), (2010). Economic input-output life cycle assessment (EIO-LCA), U.S. 2002 Industry Benchmark model. Available from: http://www.eiolca.net [Accessed 3 November 2014].

Carpenter, A. and Gardner, K., 2009. Use of industrial by-products in urban roadway infrastructure. Argument for increased industrial ecology. Journal of Industrial Ecology, 13 (6), 965-977. doi:10.1111/j.1530-9290.2009.00175.x

Carpenter, A., Gardner, K., Fopiano, J., Benson, C. and Edil, T., 2007. Life cycle based risk assessment of recycled materials in roadway construction. Waste Management, 27 (10), 1458-1464. doi:10.1016/j.wasman.2007.03.007

Caterpillar, Inc.,2012. Caterpillar performance handbook, 42nd Ed., Caterpillar, Peoria, IL.

Chatti, K., and Zaabar, I., 2012. Estimating the effects of pavement condition on vehicle operating costs (National Cooperative Highway Research Program Report No. 720). Retrieved from: http://www.trb.org/Main/Blurbs/166904.aspx

Chowdhury, T., 2011. Supporting document for the development and enhancement of the pavement maintenance decision matrices used in the needs-based analysis. Virginia Department of Transportation, Maintenance Division, Richmond, VA. 
D’Angelo, J., Harm, E., Bartoszek, J., Baumgardner, G., Corrigan, M., Cowsert, J., et al., 2008. Warmmix asphalt: European practice, Report No. FHWA-PL-08-007, Federal Highway Administration, U.S. Department of Transportation. Retrieved from: http://international.fhwa.dot.gov/pubs/pl08007/pl08007.pdf.

Eurobitume, 2011. Life cycle inventory: Bitumen. Retrieved from http://www.eurobitume.eu/hse/sustainability

European Asphalt Pavement Association and National Asphalt Pavement Association (EAPA and NAPA), 2011. The asphalt paving industry: a global perspective ( $2^{\text {nd }}$ edition). Retrieved from: http://www.eapa.org/userfiles/2/Publications/GL101-2nd-Edition.pdf

Ferrão, P. and Nhambiu, J., 2009. A comparison between conventional LCA and hybrid EIO-LCA: analyzing crystal giftware contribution to global warming potential. In: Suh, S., editor. Handbook of input-output economics in industrial ecology. The Netherlands: Springer, 219-30.

Finnveden, G., Hauschild, M., Ekvall, T., Guinée, J., Heijungs, R., Hellweg, S., Koehler, A., Pennington, D. and Suh, S., 2009. Recent developments in Life Cycle Assessment. Journal of Environmental Management, 91 (1), 1-21. http://dx.doi.org/10.1016/j.jenvman.2009.06.018.

Gaitan, L., Mehta, Y., Nolan, A., Dubois, E., Coffey, S., McCarthy, L. and Welker, A., 2013. Evaluation of the degree of blending and polymer degradation of reclaimed asphalt pavement (RAP) for warm mix asphalt. Journal of Solid Waste Technology \& Management, 39(2), 101.

Gambill, W., 1957. You can predict heat capacities. Chemical Engineering, 64, 243-248.

Giustozzi, F., Crispino, M. and Flintsch, G., 2012. Multi-attribute life cycle assessment of preventive maintenance treatments on road pavements for achieving environmental sustainability. International Journal of Life Assessment, 17 (4), 409-419. doi:10.1007/s11367-011-0375-6

Gluch, P. and Baumann, H., 2004. The life cycle costing (LCC) approach: a conceptual discussion of its usefulness for environmental decision-making. Building and Environment, 39(5), 571-580. doi:10.1016/j.buildenv.2003.10.008

Graham, D. and Midgley, N., 2000. Graphical representation of particle shape using triangular diagrams: an Excel spreadsheet method. Earth Surface Processes and Landforms, 25(13), 14731477. doi:10.1002/1096-9837(200012)25:13<1473::AID-ESP158>3.0.CO;2-C

Hamzah, M., Jamshidi, A. and Shahada, Z., 2010. Evaluation of the potential of Sasobit ${ }^{\circledR}$ to reduce required heat energy and $\mathrm{CO}_{2}$ emission in the asphalt industry. Journal of Cleaner Production,18 (18), 1859-1865. doi:10.1016/j.jclepro.2010.08.002

Hansen, K. and Copeland, A., 2014. Annual asphalt pavement industry survey on recycled materials and warm-mix asphalt usage: 2009-2013. $4^{\text {th }}$ Annual Asphalt Pavement Industry Survey, Information series 138, National Asphalt Pavement Association. Retrieved from: http://www.asphaltpavement.org/PDFs/IS138/IS138-2013_RAP-RAS-WMA_Survey_Final.pdf.

Harder, G., Le Goff, Y., Loustau, A., Martineau, Y., Heritier, B. and Romier, A., 2008. Energy and environmental gains of warm and half- warm asphalt mix: quantitative approach. Paper \#08-2456. Presented at $87^{\text {th }}$ Annual Meeting of the Transportation Research Board, Washington, D.C.

Harvey, J., et al., 2010. Pavement life cycle assessment workshop: discussion summary and guidelines. Technical Memorandum: UCPRC-TM-2010-03. Retrieved from: http://www.ucprc.ucdavis.edu/PublicationsPage.aspx

Hofstetter, P., Braunschweig, A., Mettier, T., Müller-Wenk, R. and Tietje, O., 1999. The mixing triangle: correlation and graphical decision support for LCA-based comparisons. Journal of Industrial Ecology, 3 (4), 97-115. doi:10.1162/108819899569584

Huang, Y., Bird, R. and Heidrich, O., 2009. Development of life cycle assessment tool for construction and maintenance of asphalt pavements. Journal of Cleaner Production, 17 (2), 283-296. doi:10.1016/j.jclepro.2008.06.005 
Hunkeler, D., Lichtenvort, K. and Rebitzer, G., 2008. Environmental life cycle costing. Pensacola (FL): SETAC Pr in collaboration with CRC Pr, Boca Raton (FL).

Hwang, C. and Yoon, K., 1981. Multiple attribute decision making-methods and application: a stateof-the-art survey. New York, USA: Springer-Verlag.

Illinois Interchange, 2012. Recycling/reclaiming a savings spree. Illinois Technology Transfer Center, Illinois Department of Transportation, Vol. 2012-02. Retrieved from: http://idot.illinois.gov/Assets/uploads/files/Transportation-System/Newsletters/T2/Vol201202.pdf.

International Standard Organization (ISO), 2008. ISO 15686-5: 2008. Buildings and constructed assets - Service-life planning - Part 5: Life-cycle costing, Geneva (Switzerland): International Organization for Standardization.

International Standard Organization (ISO), 2006a. ISO 14040: 2006. International Standard ISO 14040: environmental management - life cycle assessment: principles and framework, October. Geneva (Switzerland): International Organization for Standardization.

International Standard Organization (ISO), 2006b. ISO 14044: 2006. environmental management - life cycle assessment: requirements and guidelines, October. Geneva (Switzerland): International Organization for Standardization.

Jato-Espino, D., Castillo-Lopez, E., Rodriguez-Hernandez,J. and Canteras-Jordana, J., 2014. A review of application of multi-criteria decision making methods in construction. Automation in Construction, 45, 151-162. doi:10.1016/j.autcon.2014.05.013

Junnila, S., 2006. Empirical comparison of process and economic input-output life cycle assessment in service industries. Environmental Science \& Technology, 40(22), 7070-7076. doi: $\underline{10.1021 / \mathrm{es} 0611902}$

Kendall, A., 2012. Time-adjusted global warming potentials for LCA and carbon footprints. The International Journal of Life Cycle Assessment, 17, 1042-1049. doi:10.1007/s11367-012-0436-5

Kristjánsdóttir, Ó., Muench, S., Michael, L. and Burke, G., 2007. Assessing potential for warm-mix asphalt technology adoption. Transportation Research Record: Journal of the Transportation Research Board, 2040, 91-99. doi: 10.3141/2040-10

Lee, E.-B., Kim, C. and Harvey, J., 2011. Selection of pavement for highway rehabilitation based on life.cycle cost analysis. Validation of California interstate 710 project, phase 1. Transportation Research Record: Journal of the Transportation Research Board, 2227, 23-32. http://dx.doi.org/10.3141/2227-03

Lee, J., Edil, T., Tinjum, J. and Benson, C., 2010. Quantitative assessment of environmental and economic benefits of recycled materials in highway construction. Transportation Research Record: Journal of the Transportation Research Board, 2158, 138-142. doi:10.3141/2158-17

Leontief, W., 1970. Environmental repercussions and the economic structure: an input-output approach. Review of Economics and Statistics, 52, 262-271.

Lippiat, B., 2007. BEESRG 4.0: building for environmental and economic sustainability technical manual and user guide (The National Institute of Standards and Technology Report No. 7423). Retrieved from: http://fire.nist.gov/bfrlpubs/build07/art018.html

Majeau-Bettez, G., Strømman, A. and Hertwich, E., 2011. Evaluation of process- and input-outputbased life cycle inventory data with regard to truncation and aggregation issues. Environmental Science \& Technology, 45(23), 10170-10177. doi: 10.1021/es201308x

Mattila, T., Pakarinen, S. and Sokka, L., 2010. Quantifying the total environmental impacts of anindustrial symbiosis - a comparison of process-, hybrid and input-output lifecycle assessment. Environmental Science \& Technology, 44(11), 4309-4314. doi: 10.1021/es902673m 
Mladenovič, A., Turk, J., Kovač, J., Mauko, A. and Cotič, Z., 2015. Environmental evaluation of two scenarios for the selection of materials for asphalt wearing courses. Journal of Cleaner Production, 87, 683-691. doi:10.1016/j.jclepro.2014.10.013

Modarres, A., Rahimzadeh, M. and Zarrabi, M., 2014. Field investigation of pavement rehabilitation utilizing cold in-place recycling. Resources, Conservation and Recycling, 83, 112-120. doi:10.1016/j.resconrec.2013.12.011

Mohammad, L., Hassan, M., Vallabhu, B., and Kabir, M., 2015. Louisiana’s experience with WMA technologies: mechanistic, environmental, and economic analysis. ASCE-Journal of Materials in Civil Engineering, 27(6), 04014185, doi:10.1061/(ASCE)MT.1943-5533.0001143

Nicholson, A., Olivetti, E., Gregory, J. and Field, F., Kirchain, R., 2009. End-of-life LCA allocation methods: open loop recycling impacts on robustness of material selection decisions. In: Sustainable systems and technology, ISSST'09, IEEE international symposium, 1-6.

Office of Management and Budget, 2013. Discount rates for cost-effectiveness, lease purchase, and related analyses. Table of past years discount rates from Appendix C of OMB Circular No. A-94. Retrieved from: http://www.whitehouse.gov/omb/circulars a094/a94 appx-c

Robinette, C. and Epps, J., 2010. Energy, emissions, material conservation, and prices associated with construction, rehabilitation, and material alternatives for flexible pavement. Transportation Research Record: Journal of the Transportation Research Board, 2179, 10-22. doi:10.3141/2179$\underline{02}$

Rodríguez-Alloza, A., Malik, A., Lenzen, M. and Gallego, J., 2015. Hybrid input-output life cycle assessment of warm mix asphalt mixtures. Journal of Cleaner Production, 90, 171-182. doi:10.1016/j.jclepro.2014.11.035

Rubio, M., Martínez, G., Baena, L. and Moreno, F., 2012. Warm mix asphalt: an overview. Journal of Cleaner Production, 24, 76-84. doi:10.1016/j.jclepro.2011.11.053

Rubio, M., Moreno, F., Martínez-Echevarría, M., Martínez, G. and Vázquez, J., 2013. Comparative analysis of emissions from the manufacture and use of hot and half-warm mix asphalt. Journal of Cleaner Production, 41, 1-6. doi:10.1016/j.jclepro.2012.09.036

Sakhaeifar, M., Brown, E., Tran, N. and Dean, J., 2013. Evaluation of long-lasting perpetual asphalt pavement with life-cycle cost analysis. Transportation Research Record: Journal of the Transportation Research Board, 2368, 3-11. doi:10.3141/2368-01

Santos, J., Ferreira, A. and Flintsch, G., 2015a. A life cycle assessment model for pavement management: methodology and computational framework, International Journal of Pavement Engineering, 16(3), 268-286. http://dx.doi.org/10.1080/10298436.2014.942861

Santos, J., Bryce, J., Flintsch, G. and Ferreira, A., 2015b. A comprehensive life cycle costs analysis of in-place recycling and conventional pavement construction and maintenance practices. International Journal of Pavement Engineering, (in press). http://dx.doi.org/10.1080/10298436.2015.1122190

Santos, J., Bryce, J., Flintsch, G., Ferreira, A. and Diefenderfer, B., 2015c. A life cycle assessment of in-place recycling and conventional pavement construction and maintenance practices. Structure and Infrastructure Engineering: Maintenance, Management, Life-Cycle Design and Performance, 11(9), 119-1217. doi:10.1080/15732479.2014.945095

Sayagh, S., Ventura, A., Hoang, T., Francois, D. and Jullien, A., 2010. Sensitivity of the LCA allocation procedure for BFS recycled into pavement structures. Resources, Conservation and Recycling, 54(6), 348-358. doi:10.1016/j.resconrec.2009.08.011

Sheriff, Y. and Kolarik, W., 1981. Life cycle costing: concept and practice. Omega- The International Journal of Management Science, 9(3), 287-296. doi:10.1016/0305-0483(81)90035-9 
Shirodkar, P., Mehta, Y., Nolan, A., Dubois, E., Reger, D. and McCarthy, L., 2013. Development of blending chart for different degrees of blending of RAP binder and virgin binder. Resources, Conservation and Recycling, 73, 156-161. doi:10.1016/j.resconrec.2013.01.018.

Shirodkar, P., Mehta, Y., Nolan, A., Sonpal, K., Norton, A., Tomlinson, C., Dubois, E., Sullivan, P. and Sauber, R., 2011. A study to determine the degree of partial blending of reclaimed asphalt pavement (RAP) binder for high RAP hot mix asphalt. Construction and Building Materials, 25(1), 150-155. doi:10.1016/j.conbuildmat.2010.06.045.

Sol-Sánchez, M., Moreno-Navarro, F., Garcia-Travé, G. and Rubio-Gámez, M., 2016. Analysing industrial manufacturing in-plant and in-service performance of asphalt mixtures cleaner technologies. Journal of Cleaner Production, 121, 56-63. doi:10.1016/j.jclepro.2016.02.046

Somerton, W., 1992. Thermal properties and temperature-related behavior of rock/fluid systems. Developments in Petroleum Science, 37, Amsterdam: Elsevier.

Stantec Consulting Services and Lochner, H., 2007. Development of performance prediction models for Virginia department of transportation pavement management system. Virginia Department of Transportation, Richmond, VA.

Stripple, H., 2001. Life cycle assessment of road: A pilot study for inventory analysis (2nd rev. ed., Swedish Environmental Research Institute (IVL) Report B 1210 E). Retrieved from: http://www.ivl.se/publikationer/importeradebrapporterrorej/lifecycleassessmentofroadapilotstudyf orinventoryanalysissecondrevisededition.5.7df4c4e812d2da6a416800040296.html

Suh, S. and Huppes, G., 2005. Methods for life cycle inventory of a product. Journal of Cleaner Production, 13(7), 687-697. doi:10.1016/j.jclepro.2003.04.001

Suh, S., Lenzen, M., Treloar, G.J., Hondo, H., Horvath, A., Huppes, G., Jolliet, O., Klann, U., Krewitt, W., Moriguchi, Y., Munksgaard, J. and Norris, G., 2004. System boundary selection in life-cycle inventories using hybrid approaches. Environmental Science \& Technology, 38(3), 657-664. doi: $\underline{10.1021 / \mathrm{es} 0263745}$

Swarr, T., Hunkeler, D., Klöpffer, W., Pesonen, H.-L., Ciroth, A., Brent, A. and Pagan, R., 2011. Environmental life cycle costing: a code of practice. Pensacola (FL): Society of Environmental Chemistry and Toxicology (SETAC).

Tatari, O., Nazzal, M. and Kucukvar, M., 2012. Comparative sustainability assessment of warm-mix asphalts: a thermodynamic based hybrid life cycle analysis. Resources, Conservation and Recycling, 58, 18-24. doi:10.1016/j.resconrec.2011.07.005

Thenoux, G., González, A. and Dowling, R., 2007. Energy consumption comparison for different asphalt pavements rehabilitation techniques used in Chile. Resources, Conservation and Recycling, 49(4), 325-339. doi:10.1016/j.resconrec.2006.02.005

Transportation Research Board (TRB), 2000. Highway capacity manual 2000. Washington, DC: Transportation Research Board.

United States Army Corps of Engineers (US ACE), 2011. Construction equipment ownership and operating expense schedule, Region II. Document EP 1110-1-8, Vol. 2. Washington D.C.: US Army Corps of Engineers. Retrieved from: http://www.publications.usace.army.mil/USACEPublications/EngineerPamphlets.aspx?udt 4354 5_param_page $=12$

United States Energy Information Administration (US EIA), 2012. State electricity profiles 2010 (Report DOE/EIA-0348(01)/2). Retrieved from: http://www.eia.gov/electricity/state/

United Sates Energy Information Administration (US EIA), 2013. Carbon dioxide emissions coefficients. Retrieved from: http://www.eia.gov/environment/emissions/co2_vol_mass.cfm

United States Environmental Protection Agency (US EPA), 2004. AP-42: Compilation of air pollutant emission factors (Vol. 1: Stationary point and area sources, Chap. 11: Mineral products industry 11.1). Retrieved from: http://www.epa.gov/ttn/chief/ap42/ch11/index.html 
United States Environmental Protection Agency (US EPA), 2010a. Exhaust and crankcase emission factors for nonroad engine modelling - compression-ignition (Report No. NR-009d). Retrieved from: http://www.epa.gov/otaq/nonrdmdl.htm\#model

United States Environmental Protection Agency (US EPA), 2010b. Motor Vehicle Emission Simulator (MOVES). user guide for MOVES2010b (Report EPA-420-B-12-001b). Retrieved from: http://www.epa.gov/otaq/models/moves/index.htm\#user.

Vidal, R., Moliner, E., Martínez, G. and Rubio, M., 2013. Life cycle assessment of hot mix asphalt and zeolite-based warm mix asphalt with reclaimed asphalt pavement. Resources, Conservation and Recycling, 74, 101-114. doi:10.1016/j.resconrec.2013.02.018

Virginia Department of Transportation (VDOT), 2011. State of the pavement - 2011. Virginia Department of Transportation Maintenance Division. Retrieved from: http://www.virginiadot.org/info/resources/State_of_the_Pavement_2011.pdf.

Virginia Department of Transportation (VDOT), 2012a. 2012 Construction resources guidebook, Division II- Materials, Special provision copied notes (SPCNs), special provision (SPs) and Supplemental specifications (ss), updated July 8, 2014, Virginia Department of Transportation Construction Division, Central Office, Richmond. Retrieved from: http://www.virginiadot.org/business/resources/const/07ImpRev.zip

Virginia Department of Transportation (VDOT), 2012b. Business rules and user's information, dashboard 3.0. Virginia Department of Transportation. Retrieved from: http://dashboard.virginiadot.org/Help/DB\%20User\%20Guide.PDF.

Virginia Department of Transportation (VDOT), 2013. Project selection guidelines for cold pavement recycling. Virginia Department of Transportation Materials Division. Retrieved from: http://www.virginiadot.org/VDOT/Business/asset_upload_file526_3638.docx

Virginia Department of Transportation (VDOT), 2014. Manual of instructions for the materials division. Virginia Department of Transportation Materials Division. Retrieved from: http://www.virginiadot.org/business/materials-download-docs.asp

Walls, J. and Smith, M., 1998. Life-cycle cost analysis in pavement design - in search of better investment decisions (Report No. FHWA-SA-98-079), Federal Highway Administration, Washington, D.C. Retrieved from: http://isddc.dot.gov/OLPFiles/FHWA/013017.pdf

Waples, D. and Waples, J., 2004a. A review and evaluation of specific heat capacities of rocks, minerals, and surface fluids, part 1: mineral and non porous rocks. Natural Resources Researches, 13(2), 97-122. doi:10.1023/B\%3ANARR.0000032647.41046.e7

Waples, D. and Waples, J., 2004b. A review and evaluation of specific heat capacities of rocks, minerals, and surface fluids, part 2: fluids and porous rocks. Natural Resources Researches, 13(2), 123-130. doi:10.1023/B\%3ANARR.0000032648.15016.49

Weidema, B., Bauer, C., Hischier, R., Mutel, C., Nemecek, T., Reinhard, J., Vadenbo, C. and Wernet, G., 2013. The ecoinvent database: overview and methodology, Data quality guideline for the ecoinvent database version 3, www.ecoinvent.org.

West, R., Rodezno, C., Julian, G., Prowell, B., Frank, B., Osborn, L. and Kriech, T., 2014. Field performance of warm mix asphalt technologies (National Cooperative Highway Research Program Report No. 779). Transportation Research Board, Washington, D.C. Retrieved from: http://www.trb.org/Main/Blurbs/171480.aspx

The White House, 2014. FACT SHEET: Building a 21st century infrastructure: increasing public and private collaboration with the Build America investment initiative, Office of the Press Secretary. Retrieved from: http://www.whitehouse.gov/the-press-office/2014/07/17/fact-sheet-building-21stcentury-infrastructure-increasing-public-and-pr 
1 Zaumanis, M., 2014. Warm mix asphalt, K. Gopalakrishnan et al. (eds.), Climate Change, Energy, 2 Sustainability and Pavements, Green Energy and Technology, Springer-Verlag. doi:10.1007/978$3 \quad$ 3-662-44719-2 10

4 Zhao, G.-J. and Guo, P., 2012. Workability of Sasobit warm mixture asphalt. Energy Procedia, 16, 5 1230-1236. doi:10.1016/j.egypro.2012.01.196 